\title{
Critical role of WNK1 in MYC-dependent early thymocyte development
}

Robert Köchl ${ }^{1,2 *}$, Lesley Vanes ${ }^{1}$, Miriam Llorian Sopena ${ }^{1}$, Probir Chakravarty ${ }^{1}$, Harald Hartweger ${ }^{1}$, Kathryn Fountain ${ }^{1}$, Andrea White ${ }^{3}$, Jennifer Cowan ${ }^{3}$, Graham Anderson ${ }^{3}$, Victor L. J. Tybulewicz ${ }^{1,4 *}$

${ }^{1}$ The Francis Crick Institute, London, NW1 1AT, UK

${ }^{2}$ Kings College London, London, SE1 9RT, UK

${ }^{3}$ University of Birmingham, UK

${ }^{4}$ Imperial College, London W12 0NN, UK

${ }^{*}$ Correspondence to:

Victor L. J. Tybulewicz

The Francis Crick Institute,

1 Midland Road,

London, NW1 1AT, UK

Tel: +44203796 1612

Email: Victor.T@crick.ac.uk

ORCID: 0000-0003-2439-0798

or

Robert Köchl

Email: Robert.Koechl@kcl.ac.uk 
Köchl et al

\begin{abstract}
WNK1, a kinase that controls kidney salt homeostasis, also regulates adhesion and migration in $\mathrm{CD}^{+} \mathrm{T}$ cells. Wnk1 is highly expressed in thymocytes, and since migration is important for thymocyte maturation, we investigated a role for WNK1 in thymocyte development. We find that WNK1 is required for the transition of double negative (DN) thymocytes through the $\beta$-selection checkpoint and subsequent proliferation and differentiation into double positive (DP) thymocytes. Furthermore, we show that WNK1 negatively regulates LFA1-mediated adhesion and positively regulates CXCL12induced migration in DN thymocytes. Despite this, migration defects of WNK1-deficient thymocytes do not account for the developmental arrest. Instead, we show that in DN thymocytes WNK1 transduces pre-TCR signals via OXSR1 and STK39 kinases and the SLC12A2 ion co-transporter that are required for post-transcriptional upregulation of MYC and subsequent proliferation and differentiation into DP thymocytes. Thus, a pathway regulating ion homeostasis is a critical regulator of thymocyte development.
\end{abstract}

\title{
Introduction
}

With No Lysine kinase 1 (WNK1) is a member of a family of four mammalian serine/threonine-specific protein kinases that are broadly conserved across evolution and are found in all multicellular organisms (Verissimo and Jordan, 2001). Mutations in WNK1 and WNK4 result in familial hypertension due to altered salt reabsorption in the kidney, because they regulate ion transport in kidney epithelial cells (Wilson et al., 2001). WNK kinases phosphorylate and activate the related OXSR1 and STK39 kinases, which in turn phosphorylate and activate the $\mathrm{Na}^{+} \mathrm{K}^{+} \mathrm{Cl}^{-}$co-transporters SLC12A1 and SLC12A2 and the $\mathrm{Na}^{+} \mathrm{Cl}^{-}$co-transporter SLC12A3 (Rafiqi et al., 2010; Thastrup et al., 2012), allowing $\mathrm{Na}^{+}, \mathrm{K}^{+}$and $\mathrm{Cl}^{-}$ions to enter the cell. Furthermore, they phosphorylate and inhibit the $\mathrm{K}^{+} \mathrm{Cl}^{-}$co-transporters SLC12A4, SLC12A5, SLC12A6, SLC12A7 (Mercado et al., 2016), allowing $\mathrm{K}^{+}$and $\mathrm{Cl}^{-}$to leave the cell. Thus, the net 
effect of WNK kinase signaling is to promote movement of $\mathrm{Na}^{+}, \mathrm{K}^{+}$and $\mathrm{Cl}^{-}$ions into the cell. Beyond its role in ion homeostasis, WNK1 has been proposed to regulate vesicular trafficking, proliferation and cell volume (de Los Heros et al., 2018; McCormick and Ellison, 2011).

Unexpectedly, we recently showed that signaling from both the T cell antigen receptor (TCR) and from the CCR7 chemokine receptor in $\mathrm{CD}^{+} \mathrm{T}$ cells lead to activation of WNK1 (Köchl et al., 2016). Furthermore, we found that WNK1 is a negative regulator of TCR- or CCR7-induced adhesion to ICAM1 mediated by LFA1. Conversely, WNK1 is a positive regulator of chemokine-induced migration through OXSR1, STK39 and SLC12A2. As a result, WNK1-deficient T cells home less efficiently to lymphoid organs and migrate more slowly through them. Thus, a pathway that regulates salt homeostasis in the kidney, also controls T cell adhesion and migration.

Wnk1 expression levels are particularly high in the thymus (Shekarabi et al., 2013), where $\alpha \beta$ and $\gamma \delta$ T cells develop. Generation of $\alpha \beta$ T cells occurs through a series of well-defined developmental subsets. The most immature double negative (DN) thymocytes, expressing neither CD4 nor CD8, can be subdivided into DN1 (CD25CD44 $\left.{ }^{+}\right)$, DN2 $\left(\mathrm{CD}^{+} 5^{+} \mathrm{CD} 44^{+}\right)$, DN3 (CD25 $\left.{ }^{+} \mathrm{CD} 44^{-}\right)$and DN4 (CD25-CD44) subsets (Godfrey et al., 1993). Subsequently, the cells upregulate CD8 and then CD4, becoming $\mathrm{CD} 4^{-} \mathrm{CD} 8^{+}$immature single positive (ISP) cells and then $\mathrm{CD} 4^{+} \mathrm{CD} 8^{+}$double positive (DP) thymocytes. Finally, they lose expression of either CD4 or CD8 to become $\mathrm{CD}^{+}$or $\mathrm{CD} 8^{+}$single positive (4SP or $8 \mathrm{SP}$ ) cells and emigrate from the thymus as $\mathrm{CD} 4^{+}$or $\mathrm{CD} 8^{+} \mathrm{T}$ cells.

To generate T cells that have successfully rearranged both $\operatorname{TCR} \alpha$ and $\operatorname{TCR} \beta$ genes and express an $\alpha \beta T C R$ that is both restricted by self-MHC and self-tolerant, 
thymocytes need to pass three checkpoints (Carpenter and Bosselut, 2010). Thymic progenitors migrate from the bone marrow via the blood, entering the thymus at the cortico-medullary junction as DN1 cells. DN2 and DN3 thymocytes begin to re-arrange TCR $\beta$ genes and migrate to the sub-capsular zone of the cortex. If rearrangement is successful, TCR $\beta$ protein binds to pre-T $\alpha$ and together with $\operatorname{CD} 3 \gamma, \operatorname{CD} 3 \delta, \operatorname{CD} 3 \varepsilon$ and CD3 $\zeta$ forms the pre-TCR (Yamasaki and Saito, 2007). Signals from the pre-TCR are required for the survival and proliferative expansion of DN4 thymocytes, and subsequent differentiation into ISP and DP cells, a checkpoint termed $\beta$-selection (Kreslavsky et al., 2012; Mingueneau et al., 2013). Progression through this checkpoint is also supported by signals from CXCR4 and NOTCH1 (Janas et al., 2010; Maillard et al., 2006; Trampont et al., 2010).

Subsequently, DP thymocytes, now in the cortex, rearrange TCR $\alpha$ genes. If they successfully make an $\alpha \beta T C R$ that can bind weakly to self-peptide-MHC complexes, the cells undergo positive selection into 4SP and 8SP cells and migrate into the medulla (Klein et al., 2014). Alternatively, if the $\alpha \beta T C R$ binds strongly to self-peptideMHC, auto-reactive T cells are eliminated by negative selection.

In view of the important role of migration during thymocyte development, the high expression of Wnk1 in the thymus, and our previous work showing that WNK1 regulates adhesion and migration of $\mathrm{CD}^{+} \mathrm{T}$ cells, we investigated a potential role for WNK1 during thymocyte development. We find that WNK1 is required for DN thymocytes to progress past the $\beta$-selection checkpoint. We show that in DN thymocytes, WNK1 is a negative regulator of LFA1-mediated adhesion and a positive regulator of chemokine-induced migration. However, changes in migration are unlikely to cause the developmental arrest in WNK1-deficient thymocytes. Instead, WNK1, acting through OXSR1, STK39 and SLC12A2, is required for pre-TCR-induced post- 
transcriptional upregulation of MYC, and subsequent proliferation of DN4 thymocytes and differentiation into DP cells. Thus, a pathway that regulates ion homeostasis is a critical and previously unknown regulator of early thymocyte development.

\section{Results}

\section{WNK1 pathway genes expressed throughout thymic development}

To extend the previous observation that Wnk1 is expressed at a high level in the thymus (Shekarabi et al., 2013), we re-analyzed RNAseq data from multiple stages of thymic development (Hu et al., 2013), focusing on expression of WNK-family kinases and proteins in the WNK pathway. We found that Wnk1 is the only member of the WNK-family expressed in thymocytes, with high expression at all stages of development (Supplementary Figure 1). Substantially more Oxsr1 than Stk39 is expressed at all stages, except for 4SP thymocytes where the expression of Stk39 exceeds levels of Oxsr1. Of the $\mathrm{Na}^{+} \mathrm{K}^{+} \mathrm{Cl}^{-}$and $\mathrm{Na}^{+} \mathrm{Cl}^{-}$co-transporters, only S/c12a2 is expressed in the thymus. Finally, there is substantial expression of the S/c12a6 and Slc12a7 $\mathrm{K}^{+} \mathrm{Cl}^{-}$co-transporters. Thus, multiple genes in the WNK1 pathway are expressed throughout thymic development.

\section{Essential role for WNK1 in thymocyte development}

To test whether WNK1 is required during T cell development, we used the CD2Cre transgene to delete loxP-flanked (floxed) alleles of Wnk1 $\left(W n k 1^{f l}\right)$ starting at the DN2

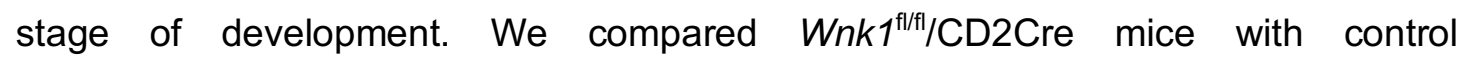
$W n k 1^{\mathrm{fl} /+} / \mathrm{CD} 2 \mathrm{Cre}$ mice in which thymocytes have homozygous or heterozygous loss of Wnk1 respectively. We found that in the absence of WNK1, there was a progressive loss of cells from the DN4 stage onwards, with a $92 \%$ reduction in numbers of ISP thymocytes and a 98-99\% reduction in DP, 4SP and 8SP thymocytes (Figure 1A-C). Analysis of Wnk1 mRNA levels showed that while Wnk1 expression was lost in DN 


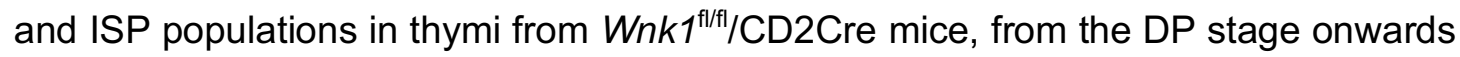
the expression levels were similar to or higher in comparison to control animals (Figure 1D), demonstrating that the few remaining DP cells are those that have failed to delete Wnk1. Hence WNK1 is absolutely required for the development of DP thymocytes.

Next, we evaluated whether the kinase activity of WNK1 is required for thymic development. We generated compound heterozygous mice with both a kinase-inactive allele $\left(W n k 1^{\text {D368A }}\right)$ and a floxed allele of $W n k 1$ and a tamoxifen-inducible Cre in the ROSA26 locus (ROSA26-CreERT2, RCE) and generated bone marrow chimeras by reconstituting irradiated $R A G 1$-deficient mice with marrow from either $W n k 1^{\text {fl/D368A}} / R C E$ mice or $W n k 1^{f l /+} / R C E$ mice as a control. Following tamoxifen treatment of these chimeras, lymphocytes are the only cell type in which all cells delete the floxed Wnk1 allele, leaving them with either a wild-type or D368A Wnk1 allele. We found that after $7 \mathrm{~d}$ of tamoxifen treatment, development of thymocytes expressing only WNK1-D368A was again very strongly blocked from the DN4 stage onwards (Figure 1E, F), demonstrating that WNK1 kinase activity is required for thymocyte development from the DN to DP stages.

\section{WNK1 is required for thymocytes to develop past the pre-TCR checkpoint}

The block in T cell development between the DN3 and DN4 and subsequent DP stages in the absence of WNK1 coincides with the $\beta$-selection checkpoint, where DN3 cells that have productively rearranged the TCR $\beta$ locus and express TCR $\beta$ protein assemble the pre-TCR. Subsequent pre-TCR signals result in survival and proliferative expansion of DN4 cells, and differentiation into DP cells. To determine if this checkpoint might be compromised in WNK1-deficient thymocytes because of a failure to assemble the pre-TCR, we assessed expression of pre-TCR components. Flow cytometric analysis of DN2 and DN3 thymocytes showed that a similar fraction $(\sim 10 \%)$ 
of both control and WNK1-deficient cells expressed intracellular TCR $\beta$, corresponding to cells that have successfully rearranged the TCR $\beta$ locus, indicating that loss of WNK1 does not impair TCR $\beta$ locus rearrangement (Figure 2A). A similar analysis of DN4 cells showed that most control cells expressed intracellular TCR $\beta$, as would be expected for cells successfully undergoing $\beta$-selection. In contrast, only $\sim 10 \%$ of WNK1-deficient DN4 cells express intracellular TCR $\beta$, similar to the percentage in DN3 cells (Figure $2 A)$. Thus, in the absence of WNK1, there is no selective expansion of TCR $\beta^{+}$cells. Cell surface levels of CD3 $\varepsilon$ and pre-T $\alpha$ in WNK1-deficient DN2 and DN3 cells were comparable to controls, while CD3\& levels were increased in WNK1-deficient DN4 cells (Figure 2B). Taken together, these results show that the developmental block in WNK1-deficient DN thymocytes is unlikely to be due to a failure to make pre-TCR subunits. Instead, the phenotype may be caused by failure of pre-TCR signaling.

To directly test this, we made use of an approach in which anti-CD3 $\varepsilon$ antibodies are injected into RAG1-deficient mice that have arrested thymocyte development at the DN3 stage because of a failure to rearrange TCR genes. RAG1-deficient DN3 thymocytes express small amounts of the CD3 proteins on the cell surface and binding of anti-CD3 $\varepsilon$ mimics a pre-TCR signal, resulting in differentiation of the thymocytes into DP cells (Levelt et al., 1993; Shinkai and Alt, 1994). As expected, injection of anti$\mathrm{CD} 3 \varepsilon$ into control $W n k 1^{\mathrm{fl/t}} / \mathrm{CD} 2 \mathrm{Cre} / \mathrm{Rag} 1^{-/-}$mice resulted in the generation of large numbers of DP thymocytes. By stark contrast, DP thymocytes were completely absent in anti-CD3 $\varepsilon$ treated $W n k 1^{\mathrm{fl/f} / \mathrm{CD}} 2 \mathrm{Cre} / \mathrm{Rag} 1^{-/-}$mice (Figure $2 \mathrm{C}$ ), indicating that WNK1 is essential for pre-TCR signaling that controls the DN-DP transition in thymocytes.

\footnotetext{
RNAseq of WNK1-deficient thymocytes reveals significant changes in 5 distinct processes
} 
To gain further insight into the role of WNK1 in this developmental transition, we used RNA sequencing (RNAseq) to analyze the transcriptome of DN3 and DN4 cells sorted

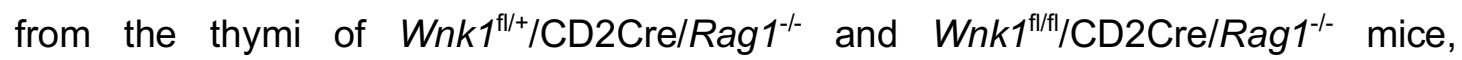
harvested 0, 3, 24 and $48 \mathrm{~h}$ after injection with anti-CD3 $\varepsilon$ (Figure 3A, B, Supplementary Table 1). Principal component analysis (PCA) of the results revealed that the biggest differences between the samples were caused by anti-CD3 $\varepsilon$ stimulation and not by genotype (Figure 3C). Both, WNK1-deficient thymocytes and control cells followed a similar trajectory on the PCA plot as a function of time after anti-CD3 $\varepsilon$ injection, suggesting that pre-TCR signaling is able to induce similar transcriptional changes in control and WNK1-deficient thymocytes. Nevertheless, comparing the transcriptomes of control and WNK1-deficient thymocytes, we identified a large number of statistically significant differentially expressed genes (DEGs) at each time point, including in unstimulated cells (Figure 3D, Supplementary Tables 2, 3).

To further characterize these changes, we carried out a process enrichment analysis taking into account all DEGs at each time point and found that most of the identified processes fit into 5 functional groups: genes associated with TCR signaling, protein translation, cytoskeleton, adhesion and cell cycle (Figure 3E). The TCR signaling and translation signatures were most enriched at the $0 \mathrm{~h}$ time point, cytoskeleton and adhesion at $48 \mathrm{~h}$, and cell cycle at $24 \mathrm{~h}$. Thus, WNK1 deficiency causes changes in several key biochemical pathways, any or all of which could be causing the developmental arrest.

\section{WNK1 deficiency does not perturb early pre-TCR-induced signaling and protein translation}

We investigated the potential contribution of each of the perturbed processes to the developmental block caused by loss of WNK1. Inspection of the TCR signaling 
signature showed that WNK1-deficient thymocytes had decreased levels of mRNA for $C d 3 d, C d 3 e, C d 3 g, L c k$ and Syk, coding for CD3 proteins and the LCK and SYK tyrosine kinases and an increase in Lcp2 mRNA, which codes for the SLP76 adapter protein (Figure 4A), suggesting that pre-TCR signaling may be perturbed, though we note that at least for $\mathrm{CD} 3 \varepsilon$, reduced mRNA level in WNK1-deficient cells did not result in reduced cell surface protein level (Figure 2B). However, analysis of transcriptional changes driven by pre-TCR stimulation showed that both control and WNK1-deficient cells upregulated Nur77 and downregulated I/2ra, Hes1, Rag2, and Ptcra to a similar extent (Figure 4B). Furthermore, anti-CD3\&-induced downregulation of surface levels of CD25 (encoded by II2ra) also occurred normally in WNK1-deficient cells (Figure 3B, 4C). These results imply that loss of WNK1 does not have a major effect on pre-TCR signaling, at least for the first $24 \mathrm{~h}$ after stimulation.

The most highly enriched processes in the RNAseq analysis were associated with protein translation, with many of the genes in these processes being downregulated in WNK1-deficient cells, particularly at the $0 \mathrm{~h}$ time point (Figure 3E, 4D). We hypothesized that this could lead to lower overall protein synthesis and might explain the developmental block. To test this, we measured levels of phosphorylated S6 (pS6), a hallmark of active translation, in DN3 and DN4 thymocytes from mice $24 \mathrm{~h}$ after injection of anti-CD3e, and also directly tested the capacity of the cells to synthesize proteins using a puromycin incorporation assay. We found that pS6 levels in WNK1deficient cells were similar to those in control cells before stimulation and higher than in controls $24 \mathrm{~h}$ after anti-CD3 $\varepsilon$ stimulation (Figure 4E). Furthermore, rates of protein synthesis were increased to a similar extent by anti-CD3 $\varepsilon$ in both control and mutant thymocytes (Figure 4F). Thus, despite the reduced expression of genes associated with translation, the absence of WNK1 does not cause substantial changes in rates of protein synthesis, and these are unlikely to explain the developmental block. 


\section{WNK1 regulates thymocyte migration and adhesion}

In the process enrichment analysis of the RNAseq data we identified cytoskeleton and adhesion signatures. At the $24 \mathrm{~h}$ time point WNK1-deficient thymocytes had increased expression of Itgb2 and Itgal, the subunits of LFA1, as well as Rap1a and Rap2a that encode GTPases required for integrin signaling, and several chemokine receptors (Ccr2, Ccr5 and Cxcr5), although Cxcr4 expression was reduced (Figure 5A); some of the same changes were also visible $48 \mathrm{~h}$ after stimulation. In agreement with this, cellsurface LFA1 was increased and CXCR4 was decreased on both WNK1-deficient DN2+DN3 and DN4 thymocytes (Figure $5 B$ ). We have previously shown that WNK1 is a negative regulator of LFA1-mediated adhesion and a positive regulator of chemokine-induced migration in $\mathrm{CD}^{+} \mathrm{T}$ cells (Köchl et al., 2016). These functions, together with the transcriptional changes seen here, suggest that WNK1 may also regulate adhesion and migration of DN thymocytes, which could account for the developmental block.

To investigate if CXCR4 can activate the WNK1 pathway in thymocytes, we stimulated primary mouse DN3 cells from Rag $1^{-1-}$ mice with CXCL12, the ligand for CXCR4, in the presence or absence of the WNK1 inhibitor WNK463 and analyzed phosphorylation of OXSR1 on Ser325, a WNK1 substrate (Vitari et al., 2005). We found that CXCL12 resulted in the phosphorylation of OXSR1, which was abrogated in WNK1 inhibitortreated cells (Figure 5C). Thus, CXCR4 transduces signals through WNK1 leading to the phosphorylation and, presumably, activation of OXSR1.

These results suggest that, as in $\mathrm{CD}^{+} \mathrm{T}$ cells, WNK1 may also regulate CXCR4induced adhesion and migration in DN thymocytes, possibilities we tested directly. We found that in response to stimulation through either CD3 $\varepsilon$ or CXCR4, or with $\mathrm{Mn}^{2+}$ which directly activates LFA1, WNK1-deficient DN3 thymocytes showed increased 
binding of ICAM1, indicating increased LFA1-mediated adhesion (Figure 5D). Furthermore, WNK1-deficient DN3 cells had reduced migration in response to CXCL12 (Figure 5E). Thus, WNK1 is a negative regulator of LFA1-mediated adhesion and a positive regulator of $\mathrm{CXCL} 12$-induced migration in DN3 thymocytes.

Loss of CXCR4 results in defective thymocyte development in part because CXCR4induced migration is required for DN thymocytes to migrate from the cortico-medullary junction where they first arrive in the thymus, to the sub-cortical zone where as DN3 cells they undergo $\beta$-selection (Trampont et al., 2010). Thus, the block in development of WNK1-deficient thymocytes may be due to defects in this stereotypical CXCR4induced migration. To address this, we generated mixed bone marrow chimeras by reconstituting irradiated B6.SJL mice (CD45. $\left.1^{+} \mathrm{CD} 45.2^{-}\right)$with an 80:20 mixture of marrow from B6.SJL mice and from either $W n k 1^{\mathrm{fl} / \mathrm{t}} / \mathrm{CD} 2 \mathrm{Cre} / \mathrm{Rag}^{-{ }^{--}}$or

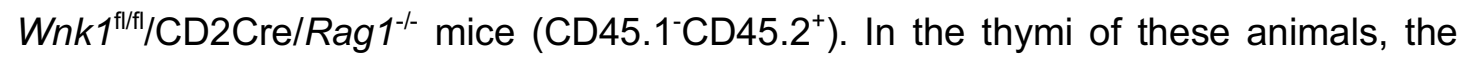
RAG1-deficient hematopoietic cells can only develop as far as the DN3 stage, and we were able to analyze their distribution within normal thymic architecture generated by the excess of wild-type B6.SJL thymocytes. We found that WNK1-deficient DN3 cells accumulated in the sub-cortical zone with a similar frequency to WNK1-expressing cells and showed no excess accumulation at the cortico-medullary junction (Figure $5 F)$. Thus, despite an in vitro migration defect, WNK1-deficient DN3 thymocytes migrate to the correct anatomical location in vivo, even when in competition with WT counterparts. Collectively these data indicate that the developmental block seen in WNK-1 deficient thymocytes is unlikely to be caused by defective localization within intra-thymic microenvironments.

To extend this, we made use of an in vitro thymocyte development assay in which DN thymocytes are cultured on OP9-DL1 cells. In this system, over the course of $7 d$, thymocyte expansion and development occurs independently of the intra-thymic 
migration events seen in the thymus in vivo. Thus, we used it to evaluate if loss of WNK1 still affected thymic development even when migration was no longer relevant, by comparing the development of $\mathrm{DN}$ thymocytes from $W n k 1^{\mathrm{fl} /+} / \mathrm{CD} 2 \mathrm{Cre}$ and Wnk $1^{\text {fl/fl/ } / C D 2 C r e ~ m i c e . ~ A s ~ e x p e c t e d, ~ w e ~ f o u n d ~ t h a t ~ W N K 1-e x p r e s s i n g ~ D N ~ t h y m o c y t e s ~}$ expanded 100 -fold in number and the majority differentiated into DP, 4SP and 8SP cells (Figure 5G). In contrast, WNK1-deficient cells did not increase in number and while most of them became DN4 cells (CD25 $\left.{ }^{-} D 44^{-}\right)$, almost none differentiated beyond the DN stage, resulting in a striking absence of DP thymocytes. Taken together, these results show that the block in T-cell development caused by WNK1 deficiency can be dissociated from its role in the regulation of thymocyte migration.

\section{WNK1 controls entry of thymocytes into S-phase}

RNAseq analysis revealed a particularly strong cell cycle signature at the $24 \mathrm{~h}$ time point, though not at 0 or $3 \mathrm{~h}$ (Figure $3 \mathrm{E}$ ). While at $3 \mathrm{~h}$ post-stimulation, induction of genes associated with progression from the early to late G1 phase of the cell cycle (CDK4, CDK6, CYCLIN D3 and CYCLIN D3) occurred normally (Supplementary

Figure 2), at $24 \mathrm{~h}$ genes encoding positive regulators of S-phase entry (CDK2, CYCLIN E1, CYCLIN E2, and E2F-, ORC- and MCM-family proteins) were downregulated in WNK1-deficient thymocytes, while negative regulators, such as Cdkn1b, Cdkn1c and Fbwx7 were upregulated (Figure 6A-C). To test whether S-phase entry is defective we measured DNA content of thymocytes from $W n k 1^{\mathrm{fl} /+} / \mathrm{CD} 2 \mathrm{Cre}$ and $W n k 1^{\mathrm{fl/fl} / C D 2 C r e}$ mice. We found that while $11 \%$ of both control and WNK1-deficient DN2 and DN3 thymocytes were in the S/G2/M phases of the cell cycle, at the DN4 stage $30 \%$ of control cells but only $5 \%$ of WNK1-deficient cells had progressed beyond the G1 phase (Figure 6D). Furthermore, loss of WNK1 abrogated the increase in cell size seen during the transition of DN3 cells to the DN4 stage, a hallmark of dividing cells (Figure 6E). Thus, WNK1 is required for DN4 thymocytes to enter the S/G2/M phases of the cell cycle. 
Köchl et al

\section{WNK1 is required for pre-TCR induced regulation of MYC}

To gain further insight into this cell cycle defect, we used a computational approach to identify transcription factors whose targets were most enriched among either all DEGs or only DEGs encoding cell cycle genes at $24 \mathrm{~h}$ (Figure 7A) and extended the analysis to test the expression levels of the identified transcription factors themselves (Figure 7B). The transcription factor, whose known target genes were both most numerous and most highly enriched within the list of all DEGs at $24 \mathrm{~h}$ was ETS1. Deletion of ETS1 impairs the development of DN3 into DP thymocytes because ETS1-deficient DN4 thymocytes are more likely to die (Eyquem et al., 2004). ETS1 regulates the expression of the anti-apoptotic Bc/2A1 gene in endothelial cells (Wei et al., 2009), suggesting that it may perform a similar function in thymocytes. However, analysis of the 5 anti-apoptotic members of the BCL2-family that are expressed in thymocytes, showed that WNK1-deficient thymocytes express substantially more $B c / 2$ and $B c / 2 / 1$ (Supplementary Figure 3A). In addition, WNK1-deficient DN2+DN3 and DN4 thymocytes did not show increased levels of active caspase 3 as would be expected if they were dying at a greater rate (Supplementary Figure 3B). Thus, it is unlikely that loss of WNK1 perturbs cell survival at the $\beta$-selection checkpoint. Furthermore, loss of ETS1 does not affect proliferation of DN4 cells (Eyquem et al., 2004), thus reduced levels of ETS1 are not the main cause of the defect in WNK1-deficient thymocytes.

Another high scoring transcription factor was MYC, whose targets were also strongly enriched within all DEGs and the more limited cell cycle gene set (Figure 7A). MYC regulates the expression of cell cycle genes, including CDK-, CYCLIN- and E2F-family proteins, many of which are dysregulated in WNK1-deficient thymocytes (Figure 6B) (Bretones et al., 2015). Indeed, 4 direct MYC targets, E2F2, E2F3, E2F4 and E2F7, were identified amongst the transcription factors most likely to cause dysregulation of cell cycle genes (Figure 7A). Furthermore, thymic development is blocked in the 
absence of MYC, because of a failure of DN thymocytes to proliferate (Dose et al., 2006; Douglas et al., 2001), similar to the phenotype in WNK1-deficient thymocytes. Thus, we hypothesized that WNK1 may be required for pre-TCR-induced proliferation in DN4 thymocytes because it regulates MYC activity.

Myc transcription in thymocytes is induced by Notch signaling (Weng et al., 2006), whereas pre-TCR signaling leads to increased MYC protein levels (Dose et al., 2006; Mingueneau et al., 2013). Myc mRNA levels were unaltered in WNK1-deficient DN3 thymocytes $24 \mathrm{~h}$ after anti-CD3e stimulation, implying that Notch regulation of Myc transcription is not affected in the absence of WNK1 (Figure 7B). The expression of another Notch target, Hes1, was also unaltered by the loss of WNK1 (Figure 4B), reinforcing the conclusion that WNK1 is not required for Notch function. In contrast, loss of WNK1 affected levels of MYC protein. Whereas anti-CD3 $\varepsilon$ stimulation resulted in increased MYC in control DN3 cells, no such rise was seen in WNK1-deficient cells

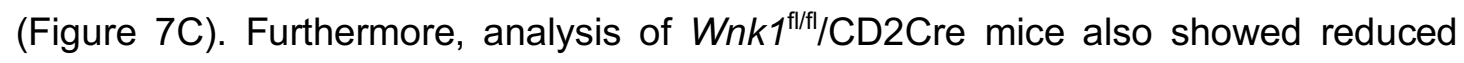
levels of MYC in both DN2+DN3 and DN4 thymocytes compared to control mice (Figure 7D). Thus, WNK1 is required for pre-TCR-induced post-transcriptional upregulation of MYC in DN thymocytes, and the failure to upregulate MYC in WNK1deficient DN cells is likely to account for their reduced proliferation and failure to differentiate into DP thymocytes.

\section{OXSR1 and STK39 are required for pre-TCR induced proliferation and regulation} of MYC

We have previously shown that in $\mathrm{CD}^{+} \mathrm{T}$ cells, WNK1 transduces signals via the related OXSR1 and STK39 kinases and the SLC12A2 ion co-transporter (Köchl et al., 2016). To test if these proteins are also required for T cell development, we evaluated thymocyte numbers in mice bearing a point mutation in Stk39 (Stk39 $\left.{ }^{\mathrm{T} 243 \mathrm{~A}}\right)$ and Oxsr1 
$\left(O x s r 1^{\top 185 A}\right)$. These residues are phosphorylated by WNK1 leading to the activation of STK39 and OXSR1, respectively and thus STK39-T243A and OXSR1-T185A can no longer be activated by WNK1. To analyze the effect of the Stk39 ${ }^{\text {T243A }}$ mutation, we compared Stk39 ${ }^{\text {T243ATT243A }}$ and control mice, whereas to assess the effect of the Oxsr1 ${ }^{\top 185 A}$ mutation we reconstituted irradiated RAG1-deficient mice with Oxsr1 ${ }^{\text {T185A/T185A }}$ and control fetal liver cells, since this homozygous mutation is lethal in late gestation (Rafiqi et al., 2010). We found that thymocyte numbers in both mutant mouse strains were normal (Figure 8A, B), suggesting that individually WNK1 activation of either STK39 or OXSR1 is not required for thymocyte development.

However, since OXSR1 and STK39 are related kinases, they could be functionally redundant with each other. We were unable to test this possibility by simply combining the Oxsr1 $1^{\top 185 A}$ and Stk39 $9^{\top 243 A}$ mutations, since embryos homozygous for both mutations die early in gestation before fetal liver cells can be harvested to make radiation chimeras (not shown). Instead, we intercrossed mice with a floxed allele of Oxsr1 $\left(O x s r 1^{f l}\right)$, the Stk39 ${ }^{\text {T243A }}$ allele and RCE, the tamoxifen-inducible Cre to generate embryos whose liver cells we used to reconstitute the hematopoietic system of irradiated RAG1-deficient mice. Subsequent treatment of the mice with tamoxifen allowed us to compare development of control thymocytes expressing wild-type OXSR1 and STK39 $\left(\mathrm{Oxsr}^{+++} / \mathrm{Stk} 39^{+/+} / \mathrm{RCE}\right)$, cells missing OXSR1 but expressing wild-

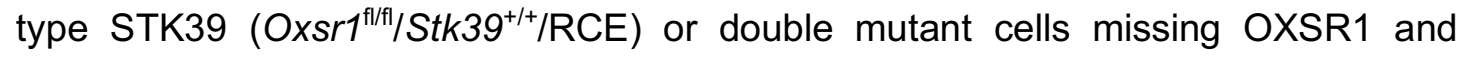

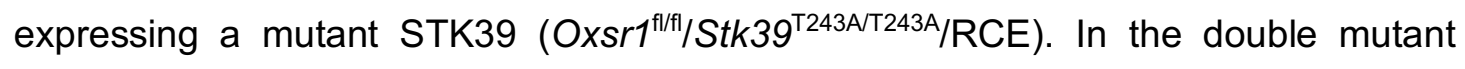
animals there was a large reduction in DN4, ISP and DP thymocytes compared to control or single mutant mice (Figure 8C), demonstrating that OXSR1 and STK39 are required for development beyond the pre-TCR checkpoint, but that the kinases have redundant function with each other. Furthermore, DN4 thymocytes deficient in both OXSR1 and STK39 had reduced entry into S-phase and reduced levels of MYC, similar to the phenotype seen in WNK1-deficient thymocytes (Figure 8D, E). Finally, we 
extended this to analysis of chimeras reconstituted with fetal livers from SLC12A2deficient embryos and found their thymocytes to also be substantially reduced at the DN4, ISP and 4SP stages, though the effect was not as large as that caused by loss of WNK1 (Figure 8F, G).

Taken together, these results show that a WNK1-OXSR1-STK39-SLC12A2 pathway that regulates ion homeostasis plays a critical role at the pre-TCR checkpoint, by transducing signals that regulate levels of MYC and subsequent thymocyte proliferation and differentiation into DP thymocytes.

\section{Discussion}

T-cell development in the thymus is a highly regulated process, and critical checkpoints at specific thymocyte stages remain poorly understood. We show here that WNK1 and its kinase activity are absolutely required for the transition of DN to DP thymocytes at the $\beta$-selection checkpoint. Specifically, in the absence of WNK1 there is a failure of the proliferative expansion of TCR $\beta^{+}$DN4 cells and subsequent differentiation into DP cells, hallmarks of $\beta$-selection. This developmental transition depends on signals from at least three receptors: pre-TCR, CXCR4 and NOTCH1 (Carpenter and Bosselut, 2010). NOTCH1 signaling appears to be unaffected by loss of WNK1, since WNK1deficient DN thymocytes have normal expression of the NOTCH1-regulated Hes1 and Myc genes. Instead, the developmental block in WNK1-deficient thymocytes is more likely caused by defective signaling from the pre-TCR, CXCR4 or both.

Our results demonstrate that WNK1 transduces signals from the pre-TCR and CXCR4 in DN thymocytes. Furthermore, we showed that WNK1-deficient cells have increased anti-CD3E- and CXCL12-induced LFA1-mediated adhesion and reduced CXCL12- 
induced migration. Thus, WNK1 is a negative regulator of adhesion and a positive regulator of migration in DN3 thymocytes. This mirrors our findings in $\mathrm{CD}^{+} \mathrm{T}$ cells, where we showed that WNK1 transduces signals from the TCR and CCR7 in CD4 ${ }^{+} \mathrm{T}$ cells to regulate both adhesion and migration (Köchl et al., 2016). WNK1 may be independently acting downstream of both the pre-TCR and CXCR4, but the two receptors may co-localize, with CXCR4 acting as a co-receptor for the pre-TCR (Trampont et al., 2010); other studies have shown that the TCR and CXCR4 physically associate to form a complex (Kumar et al., 2006). Thus, WNK1 may transduce signals from a pre-TCR-CXCR4 complex.

CXCR4-deficient mice show a strong developmental block at the $\beta$-selection checkpoint, similar to that seen in the absence of WNK1 (Janas et al., 2010; Trampont et al., 2010). This block was ascribed to mislocalization of DN3 thymocytes, with fewer cells reaching the sub-capsular zone (Trampont et al., 2010). Reduced CXCL12induced migration of WNK1-deficient DN3 thymocytes in vitro suggested that mislocalization of DN3 cells may also account for the developmental arrest in WNK1deficient thymi. However in vivo we found that WNK1-deficient DN3 thymocytes localized correctly to the sub-capsular zone and defective migration is unlikely to account for the developmental defect. This conclusion is further supported by the strong developmental arrest of WNK1-deficient thymocytes cultured on OP9-DL1 cells, a system where thymocyte development does not require migration. Since development of DP cells in this system requires CXCL12 produced by the OP9-DL1 cells, CXCR4 contributes to development through the $\beta$-selection checkpoint by more than just controlling thymocyte migration (Janas et al., 2010). Indeed, CXCR4, acting with the pre-TCR is required for proliferation of DN thymocytes as they undergo $\beta$ selection (Trampont et al., 2010). 
Analysis of WNK1-deficient DN3 thymocytes responding to pre-TCR signals showed that the initial responses of the cells are largely normal. They increase rates of translation, transiently induce expression of Nur77, downregulate expression of $/ 12$ ra, Rag2 and Ptcra, and lose surface expression of CD25, phenotypically becoming DN4 thymocytes. Furthermore, after $3 \mathrm{~h}$ of stimulation with anti-CD3e, they progress into the late G1 phase of the cell cycle as indicated by upregulation of Cdk6, Ccnd2 and Ccnd3. However, they have a profound block in entry into S-phase $24 \mathrm{~h}$ after stimulation, with reduced expression of Cdk2, Ccne1 and Ccne2, as well as genes encoding E2F-, ORC- and MCM-family proteins. In agreement with this, many fewer WNK1-deficient DN4 thymocytes entered S/G2/M phases of the cell cycle. Since proliferation of DN thymocytes is required for their differentiation into DP cells (Kreslavsky et al., 2012), this proliferative defect also accounts for the failure of WNK1deficient cells to develop into DP thymocytes.

MYC is upregulated at the $\beta$-selection checkpoint as thymocytes transit from the DN3 to DN4 stage and start to proliferate (Dose et al., 2006; Mingueneau et al., 2013). Importantly, we found that WNK1-deficient DN3 thymocytes failed to upregulate MYC in response to pre-TCR stimulation. Furthermore, many MYC target genes were dysregulated in the absence of WNK1, especially cell cycle genes. MYC-deficiency results in a similar thymic phenotype to that seen in the absence of WNK1 - reduced proliferation of DN thymocytes, failure to increase in cell size and a substantial reduction of DP thymocytes (Dose et al., 2006; Douglas et al., 2001).Taken together, we propose that the reduced proliferation of WNK1-deficient DN4 thymocytes is caused by failure to upregulate MYC, and hence reduced expression of genes required for S-phase entry. 
The upregulation of MYC at the $\beta$-selection checkpoint is post-transcriptional - MYC protein increases despite constant Myc mRNA levels (Mingueneau et al., 2013). Loss of WNK1 affects this post-transcriptional regulation since mutant DN thymocytes had reduced MYC protein, but unchanged levels of Myc mRNA. MYC is regulated at the level of protein stability. It has a short half-life, estimated to be around $20 \mathrm{~min}$, caused by rapid proteasomal degradation and its stability is regulated by phosphorylation; ERK phosphorylation stabilizes MYC, whereas GSK3 $\beta$-dependent phosphorylation results in ubiquitination of MYC by E3-ligases such as FBXW7 and subsequent proteasomal degradation (Dang, 2012; Welcker et al., 2004; Yada et al., 2004). Notably, deletion of Fbxw7 in the thymus results in high levels of MYC, increased proliferation and hypercellularity (Onoyama et al., 2007). Interestingly, the expression of Fbxw7 is increased in WNK1-deficient DN3 thymocytes $24 \mathrm{~h}$ after anti-CD3\& stimulation, which may contribute to destabilizing MYC.

Since loss of both OXSR1 and STK39 also leads to a block at the pre-TCR checkpoint, along with reduced MYC levels and decreased proliferation of DN4 thymocytes, we hypothesize that WNK1 transduces pre-TCR and CXCR4 signals via OXSR1 and STK39 to the upregulation of MYC, and hence to entry into S-phase and increased cell division. OXSR1 and STK39 phosphorylate multiple members of the SLC12A-family of ion co-transporters. Deficiency of SLC12A2, a Na $\mathrm{K}^{+} \mathrm{Cl}^{-}$transporter, showed a block at the pre-TCR checkpoint, which was less complete than that seen in the absence of WNK1. This suggests that OXSR1 and STK39 may be transducing signals that regulate MYC via several SLC12A-family proteins, including SLC12A2. The WNK1OXSR1-STK39-SLC12A2 pathway regulates ion uptake in kidney epithelial cells. Our results suggest that regulation of ion homeostasis may be essential for pre-TCR induced proliferation of thymocytes. Further studies will be needed to establish if it is 
the ion movement per se or the subsequent osmotic movement of water into the cell which is essential for thymic development.

Interestingly, among >1400 cancer cell lines, the expression of WNK1 is highest in Tcell acute lymphoblastic leukemia (T-ALL) lines, many of which originate from immature thymocytes (Cancer Cell Line Encyclopedia, CCLE https://portals.broadinstitute.org/ccle) (Barretina et al., 2012; Tan et al., 2017). Furthermore, T-ALL lines are the most sensitive to loss of WNK1, as measured by growth inhibition (CCLE) (Tsherniak et al., 2017), implying that WNK1 plays a key role in these thymically-derived tumors. Since T-ALL cells express high levels of MYC, which is essential for their proliferation (Sanchez-Martin and Ferrando, 2017), we hypothesize that WNK1 may contribute to the growth of T-ALL by maintaining high levels of MYC, making WNK1 a potential therapeutic target in this thymocyte-derived leukemia.

In summary we have shown that WNK1 is an essential regulator of early thymocyte development, where, during $\beta$-selection, it transduces signals from the pre-TCR and CXCR4 via OXSR1, STK39 and SLC12A2 that lead to upregulation of MYC, proliferation of DN4 thymocytes and differentiation into DP cells. 
Köchl et al

\section{Materials and Methods}

\section{Mice}

Mice with a conditional allele of Wnk1 containing loxP sites flanking exon 2 $\left(W n k 1^{\text {tm1Clhu }}, W n k 1^{\text {fl }}\right)$, with a conditional allele of Oxsr1 containing loxP sites flanking exons 9 and $10\left(O x s r 1^{\text {tm1.1Ssy }}\right.$, Oxsr $\left.1^{f \mid}\right)$ with a transgenic Cre recombinase under the control of the human CD2 promoter ( $\mathrm{Tg}(\mathrm{CD} 2-\mathrm{icre}) 4 \mathrm{Kio}, \mathrm{CD} 2 \mathrm{Cre})$, with a kinase inactive allele of $W n k 1\left(W n k 1^{\text {tm1.1Tyb }}, W n k 1^{\mathrm{D} 368 \mathrm{~A}}\right)$, with a tamoxifen-inducible Cre in the

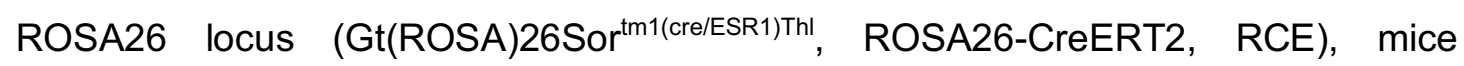
expressing OXSR1-T185A (Oxsr1 ${ }^{\text {tm1.1Arte }}$, Oxsr1 $\left.{ }^{\text {T185A }}\right)$, STK39-T243A (Stk39 $9^{\text {tm1.1Arte }}$,

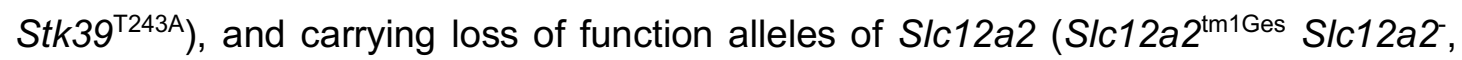
imported from MMRRC) and Rag1 (Rag1 $\left.1^{\mathrm{tm} 1 \mathrm{Mom}}, \operatorname{Rag}^{-}\right)$have been described before (de Boer et al., 2003; de Luca et al., 2005; Flagella et al., 1999; Köchl et al., 2016; Lin et al., 2011; Mombaerts et al., 1992; Rafiqi et al., 2010; Xie et al., 2009). Mice with a deleted allele of $W n k 1\left(W n k 1^{\mathrm{tm} 1.1 \mathrm{Clhu}}, W n k 1^{-}\right)$were generated by crossing $W n k 1^{\mathrm{fl} /+}$ mice with C57BL/6J.129S4-Tg(Prm-cre)70Og/Nimr mice that delete loxP-flanked alleles in the male germline (O'Gorman et al., 1997). All mice were bred and maintained on a C57BL/6J background at the MRC National Institute for Medical Research which became the Francis Crick Institute. All experiments were carried out under the authority of a Project Licence granted by the UK Home Office.

\section{Radiation chimeras}

To generate radiation chimeras, either bone marrow cells were harvested from $W n k 1^{f / /+} \mathrm{RCE}$ or $W n k 1^{\mathrm{fl} / \mathrm{D} 368 \mathrm{~A}} \mathrm{RCE}$ mice, or fetal livers were harvested from E14.5 embryos with the required genotypes $\left(\mathrm{Oxsr}^{+/+}\right.$and Oxsr1 ${ }^{\text {T185ATT185A; }}$

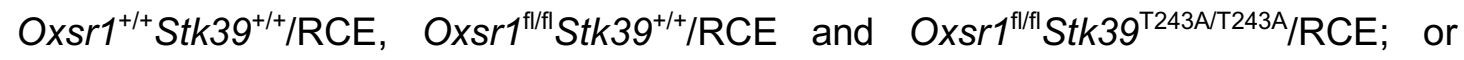
S/c12a $2^{+/-}$and S/c12a2 $\left.2^{-/}\right)$. RAG1-deficient animals (5-8 weeks of age) were irradiated with 5Gy using a ${ }^{137} \mathrm{Cs}$-source, and then reconstituted intravenously with at least $1 \times 10^{6}$ 
bone marrow cells/recipient or $0.5 \times 10^{6}$ fetal liver cells/recipient. All chimeric animals received Baytril in their drinking water $(0.02 \%$, Bayer Healthcare) for at least 4 weeks post-transplantation. If required, 8-20 weeks after reconstitution chimeric mice were injected intraperitoneally for $3 \mathrm{~d}$ with $2 \mathrm{mg} /$ day of tamoxifen (Sigma) re-suspended at $20 \mathrm{mg} / \mathrm{ml}$ in corn oil (Sigma) and analyzed $7 \mathrm{~d}$ after start of tamoxifen treatment.

\section{Flow Cytometry, antibodies, cytokines and other materials}

Flow cytometry was carried out using standard techniques with pre-titered antibodies. Antibodies for stimulations and flow cytometry against the following proteins were obtained from BioLegend, eBioscience or BD Pharmingen (clone names indicated in parentheses): B220 (RA3-6B2), CD3ع (2C11), CD4 (RM4-5 or GKL-5), CD8 (53-6.7), CD11b (M1/70), CD11c (N418), CD19 (1D3) CD25 (3C7 or PC-61.5 or 7D4), CD44 (IM7), CD45.2 (104), DX5, GR-1 (RB6-8C5), LFA-1 (M17/4), NK1.1 (PK136), PTCRA (2F5), TCRß (H57-597 or IP26), TCRyס (GL3), Thy1.1 (OX-7), Thy1.2 (53-2.1). Further reagents: anti-active Caspase 3 (C92-605, BD Pharmingen), anti-CXCR4 (ID9, BD Pharmingen), anti-MYC (Y69, Abcam), anti-pS325-OXSR1/pS383-STK39 (MRCPPU), anti-pS235/pS236-S6 (D57.2.2E, Cell Signaling); 7AAD, Foxp3/Transcription factor staining buffer set (eBioscience), mouse CXCL12, mouse ICAM1-Fc (R\&D systems), FxCycle Violet Stain, LIVE/DEAD NearlR (Thermo Fisher), Zombie Aqua (Biolegend). If not stated otherwise antibody dilutions were 1:200 for flow cytometry and thymocyte enrichment, and 1:1000 for immunoblotting experiments. If not otherwise stated antibodies to exclude lineage were a mixture of antibodies against the proteins B220, CD3, CD4, CD8, CD11b, CD11c, CD19, DX5, GR-1, NK1.1, TCRß and TCRyס. For the analysis of intracellular phospho-S6 levels single cell suspensions of thymocytes were fixed in $1 \%$ PFA for $15 \mathrm{~min}$ at room temperature and then permeabilized with $0.5 \%$ Triton $\mathrm{X}-100$ for $15 \mathrm{~min}$ at room temperature. Thymocytes were washed 2x with PBS, containing 0.5\% FCS before adding anti-pS235/pS236-S6 (1:50) and antibodies against surface markers in PBS with $0.5 \%$ FCS. Cells were 
analyzed by flow cytometry. For the analysis of intracellular MYC or active Caspase 3, single cell suspensions of thymocytes were first stained with antibodies against surface markers and then fixed for 20 min with BD Fix/Perm solution, before being washed $2 x$ with BD Perm/Wash buffer and incubated with anti-MYC (1:400) or anti-activeCaspase 3-PE (1:50) in Perm/Wash buffer for 30 min. After 2 further washes with BD Perm/Wash buffer cells were analyzed by flow cytometry. For the analysis of DNA content single cell suspensions of thymocytes were first stained with antibodies against surface markers and then fixed with for 20 min with Fix/Perm buffer from the Foxp3 kit, before being washed $3 x$ with Perm/Wash buffer from the kit and incubated in 7AAD or with FxCycle Violet Stain diluted 1:400 or 1:1000, respectively, into Perm/Wash buffer for 30 min. 7AAD and FxCycle Violet Stain fluorescence was analyzed by flow cytometry, with the fluorescence parameter set to linear; in all other cases, fluorescence was acquired on a logarithmic scale.

\section{RNA sequencing (RNAseq)}

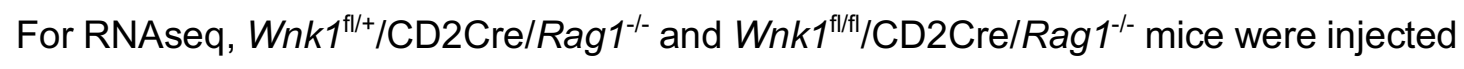
with anti-CD3 $\varepsilon(150 \mu \mathrm{g})$. Thymi were harvested 3, 24 and $48 \mathrm{~h}$ later. Thymi from uninjected mice were used for the $0 \mathrm{~h}$ time point. CD44- Thy $1.2^{+}$thymocytes were sorted into Trizol (Life Technologies) using a Beckman Coulter MoFlo XDP cell sorter. RNA was purified using the RNEasy mini kit (Qiagen). Stranded polyA-enriched libraries were made using the KAPA mRNA HyperPrep Kit (Roche) according to the manufacturer's instructions and sequenced in the HiSeq 4000 (Illumina), collecting 2873 million single-end reads of 75 bases per sample. Read trimming and adapter removal were performed using Trimmomatic (version 0.36) (Bolger et al., 2014). The RSEM package (version 1.2.31) (Li and Dewey, 2011), and STAR (version 2.5.2a) (Dobin et al., 2013) were used to align reads to the mouse genome (Ensembl GRCm38 release 86 ) and to obtain gene level counts. For RSEM, all parameters were run as default except "--forward-prob" that was set to "0". Differential expression analysis was 
carried out with DESeq2 package (Love et al., 2014). Genes were considered to be differentially expressed with adjusted $p$-value (padj) $\leq 0.05$. For data processing in Metacore, only genes with an average expression of transcripts per million (TPM) $>3$ over all conditions were considered. All RNAseq data has been deposited in Gene Expression Omnibus (GEO) with accession number GSE136210. Reviewers can access this data using the following token: gruleowavdgxlqr.

For the re-analysis of RNAseq data from thymocyte subsets (Hu et al., 2013), Fastq files were obtained from the Gene Expression Omnibus (GSE48138). Gene-level TPM abundance estimates were calculated with RSEM using STAR to align reads against the NCBIM37 (mm9) genome assembly with Ensembl release 67 transcript annotations.

\section{Q-PCR for Wnk1 mRNA}

Up to $5 \times 10^{4}$ cells of each thymic population from thymi of control or WNK1-deficient animals were sorted directly into RLT lysis buffer, total RNA was extracted with an RNAEasy Plus Micro Kit (Qiagen) and cDNA was synthesized with a Superscript III kit (Life Technologies). Samples were analyzed on an ABI 7900 using a TaqMan gene expression assay (Life Technologies) spanning exon1 and exon 2 of Wnk1. Data was normalized to Hprt1 and analyzed using the comparative threshold cycle method.

\section{Enrichment of double negative thymocytes}

Double negative thymocytes were enriched by negative selection. Single-cell suspensions were incubated with biotin-conjugated antibodies against lineage markers B220, CD3, CD4, CD8, CD11b, CD11c, CD19, DX5, GR-1, NK1.1, TCRß and TCRүס,, and were then washed and incubated with Streptavidin-conjugated magnetic beads (Dynabeads, Life Technologies) and cells bound to the beads removed according to the manufacturer's instructions. 
Köchl et al

\section{Stimulation of thymocyte development and signaling in RAG1-deficient mice}

Development of double positive thymocytes was induced by a single intraperitoneal injection of $30 \mu \mathrm{g}$ anti-CD3 $\varepsilon$ antibody into RAG1-deficient mice, followed by harvesting the thymus for flow cytometric analysis $4 \mathrm{~d}$ later. For all other experiments where preTCR signaling responses were being measured, RAG1-deficient mice were injected with $150 \mu \mathrm{g}$ anti-CD3e.

\section{MetaCore analysis}

The lists of filtered differentially expressed genes were uploaded to MetaCore and analyzed with the Process Networks analysis and Transcription Factor analysis modules (MetaCore version 19.1 build 69600).

\section{Heatmaps}

Selected genes from a number of enriched processes were used to generate a heatmap using the R package pheatmap. Genes were clustered using an Euclidean distance matrix and complete linkage clustering. Red indicates higher expression and blue indicates low expression relative to the mean expression of the gene across all samples.

\section{Protein synthesis assay}

Mice were injected intraperitoneally with $150 \mu \mathrm{g}$ anti-CD3 or left untreated. $24 \mathrm{~h}$ later thymi were harvested. Single cell suspensions were prepared and either pre-treated with $10 \mu \mathrm{M}$ cycloheximide for $30 \mathrm{~min}$ or not, before being incubated with $5 \mu \mathrm{M}$ Opropargyl-puromycin (OPP) or not for $30 \mathrm{~min}$ at $37^{\circ} \mathrm{C}$. Thymocytes were washed $2 \mathrm{x}$ in PBS $0.5 \%$ FCS, incubated with surface antibodies and fixed with 1\% PFA for 15 min at room temperature. Cells were permeabilized with $0.5 \%$ Triton for $15 \mathrm{~min}$ at room 
temperature, washed $2 x$ with PBS $0.5 \%$ FCS and then stained with the Click-it Plus OPP Protein Synthesis Kit Alexa Fluor 647 (C10458, Thermo Fisher) according to the manufacturer's instructions. Cells were washed 2x PBS 0.5\% FCS and analyzed by flow cytometry.

\section{Adhesion assays}

Binding of ICAM1 complexes to primary mouse thymocytes was analyzed as described (Konstandin et al., 2006). Soluble ICAM1-Fc-F(ab') ${ }_{2}$ complexes were generated by diluting APC-labeled goat anti-human IgG $F(a b)_{2}$ fragments (109-135-098, Jackson Immunoresearch) 1:6.25 with ICAM1-Fc $(200 \mu \mathrm{g} / \mathrm{ml}$ final) in HBSS and incubated for 30 min in HBSS at $4^{\circ} \mathrm{C}$. Thymocytes were rested for $3 \mathrm{~h}$ in IMDM, $5 \%$ FCS at $37^{\circ} \mathrm{C}$, centrifuged and re-suspended in HBSS, 0.5\% BSA. Each adhesion reaction (50 $\mu \mathrm{l})$ contained $20 \times 10^{6}$ cells $/ \mathrm{ml}, 25 \mu \mathrm{g} / \mathrm{ml}$ ICAM1 complex and the appropriate stimulus and was incubated at $37^{\circ} \mathrm{C}$ for the indicated times. Cells were fixed in PFA for 20 min and binding of ICAM1 complexes to CD25+CD44- DN2+DN3 thymocytes analyzed by flow cytometry.

\section{Migration assays}

Migration assays were carried out in 96-well Transwell plates, containing polycarbonate filters ( $5 \mu \mathrm{m}$ pore size, Corning). Transwell filters were coated overnight with $500 \mathrm{ng} / \mathrm{ml}$ mouse ICAM1-Fc in PBS and blocked with PBS, 2\% BSA for $2 \mathrm{~h}$. The receiver plate was filled with RPMI, 0.5\% BSA, containing CXCL12 (100 ng/ml) or no chemokine, and $4 \times 10^{4}$ double negative thymocytes in RPMI, $0.5 \%$ BSA were added to each well of the filter plate. After $5 \mathrm{~h}$ the filter plate was removed, EDTA was added to each well (40 mM final concentration) and the cells were transferred to 96 well Vbottom plates, spun, re-suspended in PBS, $0.5 \%$ BSA, and analyzed on a flow cytometer. Percentage migration was calculated by dividing the number of cells that 
migrated through the filter by the total number of cells that had been added to each well.

\section{Immunoblotting}

DN3 thymocytes from indicated mouse lines were enriched by negative depletion with anti-CD44 and rested for at least 90 minutes in IMDM, 5\% FCS at $37^{\circ} \mathrm{C}$. During the last 60 minutes, either DMSO or $10 \mu$ M WNK463 (HY-100626, Insight Biotechnology) was added to the cell suspensions. If required, cells were stimulated with CXCL12 (500 $\mathrm{ng} / \mathrm{ml}$ ) for $1 \mathrm{~min}$. Subsequent immunoblotting analysis was performed as described previously (Degasperi et al., 2014; Reynolds et al., 2002). The following antibodies were used for detection of proteins by Western blotting: anti-ERK2 (C-14, Santa Cruz), anti-pS325-OXSR1/pS383-STK39 (MRC-PPU).

\section{Histology}

Lethally irradiated B6.SJL mice were reconstituted with an 80:20 mixture of bone

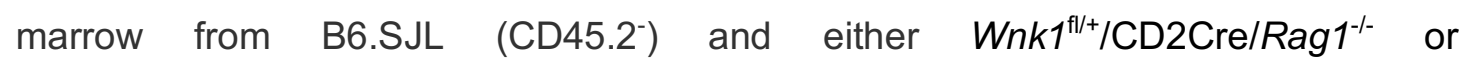
$W n k 1^{f / / f l} / C D 2 C r e / R a g 1^{-/-}$mice (both $C D 45.2^{+}$). Thymic tissue was isolated from the chimeras 8-12 weeks after reconstitution, and frozen $7 \mu \mathrm{m}$ sections were cut and the fixed in acetone. Sections were stained with the following antibodies: ERTR5 (a gift from Dr W van Ewijk, Riken Research Centre for Allergy and Immunology, Yokohama, Japan) and detected with goat anti-rat IgM coupled to AlexaFluor647, biotinylated antiCD45.2 detected with streptavidin-AlexaFluor555, anti-CD25 coupled to FITC, antiCD11b coupled to eFluor450, and anti-CD11c coupled to eFluor450. For confocal quantification, a minimum of three separate thymus sections from each mouse were analyzed at least $10 \mu \mathrm{m}$ apart, and the frequency of $C D 45.2^{+} \mathrm{CD} 25^{+} \mathrm{CD} 11 \mathrm{~b}^{-} \mathrm{CD} 11 \mathrm{c}^{-}$ cells was recorded in the subcapsular zone, cortex and cortico-medullary junction (CMJ) in a set area as described (Cowan et al., 2014). The CMJ was defined by ERTR5 
staining for medullary epithelial cells. Images were obtained using a Zeiss LSM 780 microscope and analyzed using Zeiss LSM software.

\section{In vitro thymocyte development}

OP9-DL1 cells were maintained as previously described (Ciofani and Zuniga-Pflucker, 2005). DN2+DN3 thymocytes (Lineage-, Thy $1.2^{+}, C D 25^{+}$) were sorted and for each experimental condition, 25,000 cells were cultured with $10 \mathrm{ng} / \mathrm{ml} \mathrm{IL7} \mathrm{in} \mathrm{48-well} \mathrm{plates}$ that had been previously seeded with 10,000 irradiated OP9-DL1 cells. Cells were cultured for $7 \mathrm{~d}$ and then analyzed by flow cytometry.

\section{Statistical Analysis}

All statistical comparisons were carried out using the nonparametric two-tailed MannWhitney test, Hypergeometric test, Wald test, or two-way ANOVA. The specific analysis used is described in each Figure Legend, along with the number of times experiments were carried out and the number of samples ( $n$ numbers) for each experiment. $\mathrm{N}$ numbers always refer to biological repeats, not to technical repeats. Biological repeats were defined as experiments carried out on different animals, or on cells from different animals. Repeat measurements on cells from the same animal were defined as technical repeats. Only biological repeats were used for statistical analysis. No outliers were removed and no experiments were excluded.

\section{Author contributions}

RK, LV, HH, KF, AW, JC carried out experiments and analyzed data, MLS and PC analyzed data, RK and VLJT designed the study and wrote the manuscript, GA and VLJT supervised the work.

\section{Acknowledgments}


bioRxiv preprint doi: https://doi.org/10.1101/2020.06.11.147017; this version posted June 12, 2020. The copyright holder for this preprint (which was not certified by peer review) is the author/funder, who has granted bioRxiv a license to display the preprint in perpetuity. It is made available under aCC-BY 4.0 International license.

Köchl et al

We thank George Kassiotis, Andreas Wack and Edina Schweighoffer for critical reading of the manuscript. We thank Richard Mitter for help with bioinformatics analysis. We thank the Flow Cytometry, Advanced Sequencing, and Biological Research Facility of the Francis Crick Institute for flow cytometry, RNA sequencing and animal husbandry respectively. We thank Chou-Long Huang, Dario Alessi and Sung-Sen Yang for mouse strains. VLJT was supported by the UK Medical Research Council (Programme U117527252) and by the Francis Crick Institute which receives its core funding from Cancer Research UK (FC001194), the UK Medical Research Council (FC001194), and the Wellcome Trust (FC001194).

\section{Declaration of Interests}

The authors declare no competing interests. 


\section{References}

Barretina, J, et al. 2012. The Cancer Cell Line Encyclopedia enables predictive modelling of anticancer drug sensitivity. Nature 483:603-607. doi: 10.1038/nature11003.

Bolger, AM, Lohse, M, Usadel, B. 2014. Trimmomatic: a flexible trimmer for Illumina sequence data. Bioinformatics 30:2114-2120. doi: 10.1093/bioinformatics/btu170.

Bretones, G, Delgado, MD, Leon, J. 2015. Myc and cell cycle control. Biochim. Biophys. Acta 1849:506-516. doi: 10.1016/j.bbagrm.2014.03.013.

Carpenter, AC, Bosselut, R. 2010. Decision checkpoints in the thymus. Nat. Immunol. 11:666-673. doi: 10.1038/ni.1887.

Ciofani, M, Zuniga-Pflucker, JC. 2005. Notch promotes survival of pre-T cells at the beta-selection checkpoint by regulating cellular metabolism. Nat. Immunol. 6:881-888.

Cowan, JE, et al. 2014. Differential requirement for CCR4 and CCR7 during the development of innate and adaptive alphabetaT cells in the adult thymus. J. Immunol. 193:1204-1212. doi: 10.4049/jimmunol.1400993.

Dang, CV. 2012. MYC on the path to cancer. Cell 149:22-35. doi: 10.1016/j.cell.2012.03.003.

de Boer, J, et al. 2003. Transgenic mice with hematopoietic and lymphoid specific expression of Cre. Eur. J. Immunol. 33:314-325.

de Los Heros, P, Pacheco-Alvarez, D, Gamba, G. 2018. Role of WNK Kinases in the Modulation of Cell Volume. Curr. Top. Membr. 81:207-235. doi: 10.1016/bs.ctm.2018.08.002.

de Luca, C, Kowalski, TJ, Zhang, Y, Elmquist, JK, Lee, C, Kilimann, MW, Ludwig, T, Liu, SM, Chua, SC, Jr. 2005. Complete rescue of obesity, diabetes, and 
infertility in $\mathrm{db} / \mathrm{db}$ mice by neuron-specific LEPR-B transgenes. J. Clin. Invest. 115:3484-3493. doi: 10.1172/JCI24059.

Degasperi, A, Birtwistle, MR, Volinsky, N, Rauch, J, Kolch, W, Kholodenko, BN. 2014. Evaluating strategies to normalise biological replicates of Western blot data. PLoS One 9:e87293. doi: 10.1371/journal.pone.0087293.

Dobin, A, Davis, CA, Schlesinger, F, Drenkow, J, Zaleski, C, Jha, S, Batut, P, Chaisson, M, Gingeras, TR. 2013. STAR: ultrafast universal RNA-seq aligner. Bioinformatics 29:15-21. doi: 10.1093/bioinformatics/bts635.

Dose, M, Khan, I, Guo, Z, Kovalovsky, D, Krueger, A, von Boehmer, H, Khazaie, K, Gounari, F. 2006. c-Myc mediates pre-TCR-induced proliferation but not developmental progression. Blood 108:2669-2677. doi: 10.1182/blood-200602-005900.

Douglas, NC, Jacobs, H, Bothwell, AL, Hayday, AC. 2001. Defining the specific physiological requirements for c-Myc in T cell development. Nat. Immunol. 2:307-315. doi: 10.1038/86308.

Eyquem, S, Chemin, K, Fasseu, M, Bories, JC. 2004. The Ets-1 transcription factor is required for complete pre-T cell receptor function and allelic exclusion at the $\mathrm{T}$ cell receptor beta locus. Proc. Natl. Acad. Sci. USA 101:15712-15717. doi: 10.1073/pnas.0405546101.

Flagella, $\mathrm{M}$, et al. 1999. Mice lacking the basolateral Na-K-2Cl cotransporter have impaired epithelial chloride secretion and are profoundly deaf. J. Biol. Chem. 274:26946-26955.

Godfrey, DI, Kennedy, J, Suda, T, Zlotnik, A. 1993. A developmental pathway involving four phenotypically and functionally distinct subsets of CD3-CD4-CD8- triplenegative adult mouse thymocytes defined by CD44 and CD25 expression. J. Immunol. 150:4244-4252.

Hu, G, Tang, Q, Sharma, S, Yu, F, Escobar, TM, Muljo, SA, Zhu, J, Zhao, K. 2013. Expression and regulation of intergenic long noncoding RNAs during $\mathrm{T}$ cell 
development and differentiation. Nat. Immunol. 14:1190-1198. doi: 10.1038/ni.2712.

Janas, ML, Varano, G, Gudmundsson, K, Noda, M, Nagasawa, T, Turner, M. 2010. Thymic development beyond beta-selection requires phosphatidylinositol 3kinase activation by CXCR4. J. Exp. Med. 207:247-261. doi: 10.1084/jem.20091430.

Klein, L, Kyewski, B, Allen, PM, Hogquist, KA. 2014. Positive and negative selection of the T cell repertoire: what thymocytes see (and don't see). Nat. Rev. Immunol. 14:377-391. doi: 10.1038/nri3667.

Köchl, R, et al. 2016. WNK1 kinase balances T cell adhesion versus migration in vivo. Nat. Immunol. 17:1075-1083. doi: 10.1038/ni.3495.

Konstandin, MH, Sester, U, Klemke, M, Weschenfelder, T, Wabnitz, GH, Samstag, Y. 2006. A novel flow-cytometry-based assay for quantification of affinity and avidity changes of integrins. J. Immunol. Methods 310:67-77. doi: 10.1016/j.jim.2005.12.005.

Kreslavsky, T, Gleimer, M, Miyazaki, M, Choi, Y, Gagnon, E, Murre, C, Sicinski, P, von Boehmer, H. 2012. beta-Selection-induced proliferation is required for alphabeta $\mathrm{T}$ cell differentiation. Immunity 37:840-853. doi: 10.1016/j.immuni.2012.08.020.

Kumar, A, Humphreys, TD, Kremer, KN, Bramati, PS, Bradfield, L, Edgar, CE, Hedin, KE. 2006. CXCR4 physically associates with the T cell receptor to signal in T cells. Immunity 25:213-224. doi: 10.1016/j.immuni.2006.06.015.

Levelt, CN, Mombaerts, P, Iglesias, A, Tonegawa, S, Eichmann, K. 1993. Restoration of early thymocyte differentiation in T-cell receptor beta-chain-deficient mutant mice by transmembrane signaling through CD3 epsilon. Proc. Natl. Acad. Sci. USA 90:11401-11405. doi: 10.1073/pnas.90.23.11401. 
Li, B, Dewey, CN. 2011. RSEM: accurate transcript quantification from RNA-Seq data with or without a reference genome. BMC Bioinformatics 12:323. doi: 10.1186/1471-2105-12-323.

Lin, $\mathrm{SH}$, et al. 2011. Impaired phosphorylation of $\mathrm{Na}(+)-\mathrm{K}(+)-2 \mathrm{Cl}(-)$ cotransporter by oxidative stress-responsive kinase-1 deficiency manifests hypotension and Bartter-like syndrome. Proc Natl Acad Sci U S A 108:17538-17543. doi: 10.1073/pnas.1107452108.

Love, MI, Huber, W, Anders, S. 2014. Moderated estimation of fold change and dispersion for RNA-seq data with DESeq2. Genome Biol. 15:550. doi: 10.1186/s13059-014-0550-8.

Maillard, I, et al. 2006. The requirement for Notch signaling at the \{beta\}-selection checkpoint in vivo is absolute and independent of the pre-T cell receptor. J. Exp. Med. 203:2239-2245.

McCormick, JA, Ellison, DH. 2011. The WNKs: atypical protein kinases with pleiotropic actions. Physiol. Rev. 91:177-219. doi: 10.1152/physrev.00017.2010.

Mercado, A, et al. 2016. With no lysine L-WNK1 isoforms are negative regulators of the K+-Cl- cotransporters. Am. J. Physiol. Cell Physiol. 311:C54-66. doi: 10.1152/ajpcell.00193.2015.

Mingueneau, M, et al. 2013. The transcriptional landscape of alphabeta T cell differentiation. Nat. Immunol. 14:619-632. doi: 10.1038/ni.2590.

Mombaerts, P, lacomini, J, Johnson, RS, Herrup, K, Tonegawa, S, Papaioannou, VE. 1992. RAG-1-deficient mice have no mature B and T lymphocytes. Cell 68:869877.

O'Gorman, S, Dagenais, NA, Qian, M, Marchuk, Y. 1997. Protamine-Cre recombinase transgenes efficiently recombine target sequences in the male germ line of mice, but not in embryonic stem cells. Proc. Natl. Acad. Sci. USA 94:1460214607. 
Onoyama, I, Tsunematsu, R, Matsumoto, A, Kimura, T, de Alboran, IM, Nakayama, K, Nakayama, KI. 2007. Conditional inactivation of Fbxw7 impairs cell-cycle exit during $\mathrm{T}$ cell differentiation and results in lymphomatogenesis. J. Exp. Med. 204:2875-2888. doi: 10.1084/jem.20062299.

Rafiqi, FH, Zuber, AM, Glover, M, Richardson, C, Fleming, S, Jovanovic, S, Jovanovic, A, O'Shaughnessy, KM, Alessi, DR. 2010. Role of the WNK-activated SPAK kinase in regulating blood pressure. EMBO Mol. Med. 2:63-75. doi: 10.1002/emmm.200900058.

Reynolds, LF, Smyth, LA, Norton, T, Freshney, N, Downward, J, Kioussis, D, Tybulewicz, VLJ. 2002. Vav1 transduces T cell receptor signals to the activation of phospholipase C-y1 via phosphoinositide 3-kinase-dependent and -independent pathways. J. Exp. Med. 195:1103-1114.

Sanchez-Martin, M, Ferrando, A. 2017. The NOTCH1-MYC highway toward T-cell acute lymphoblastic leukemia. Blood 129:1124-1133. doi: 10.1182/blood-201609-692582.

Shekarabi, M, Lafreniere, RG, Gaudet, R, Laganiere, J, Marcinkiewicz, MM, Dion, PA, Rouleau, GA. 2013. Comparative analysis of the expression profile of Wnk1 and Wnk1/Hsn2 splice variants in developing and adult mouse tissues. PLoS One 8:e57807. doi: 10.1371/journal.pone.0057807.

Shinkai, Y, Alt, FW. 1994. CD3 epsilon-mediated signals rescue the development of CD4+CD8+ thymocytes in RAG-2-/- mice in the absence of TCR beta chain expression. Int. Immunol. 6:995-1001. doi: 10.1093/intimm/6.7.995.

Tan, SH, Bertulfo, FC, Sanda, T. 2017. Leukemia-Initiating Cells in T-Cell Acute Lymphoblastic Leukemia. Front. Oncol. 7:218. doi: 10.3389/fonc.2017.00218. Thastrup, JO, Rafiqi, FH, Vitari, AC, Pozo-Guisado, E, Deak, M, Mehellou, Y, Alessi, DR. 2012. SPAK/OSR1 regulate NKCC1 and WNK activity: analysis of WNK isoform interactions and activation by T-loop trans-autophosphorylation. Biochem. J. 441:325-337. doi: 10.1042/BJ20111879. 
Trampont, PC, Tosello-Trampont, AC, Shen, Y, Duley, AK, Sutherland, AE, Bender, TP, Littman, DR, Ravichandran, KS. 2010. CXCR4 acts as a costimulator during thymic beta-selection. Nat. Immunol. 11:162-170. doi: 10.1038/ni.1830.

Tsherniak, A, et al. 2017. Defining a Cancer Dependency Map. Cell 170:564-576. doi: 10.1016/j.cell.2017.06.010.

Verissimo, F, Jordan, P. 2001. WNK kinases, a novel protein kinase subfamily in multicellular organisms. Oncogene 20:5562-5569. doi: 10.1038/sj.onc.1204726.

Vitari, AC, Deak, M, Morrice, NA, Alessi, DR. 2005. The WNK1 and WNK4 protein kinases that are mutated in Gordon's hypertension syndrome phosphorylate and activate SPAK and OSR1 protein kinases. Biochem. J. 391:17-24. doi: 10.1042/BJ20051180.

Wei, G, et al. 2009. Ets1 and Ets2 are required for endothelial cell survival during embryonic angiogenesis. Blood 114:1123-1130. doi: 10.1182/blood-2009-03211391.

Welcker, M, Orian, A, Jin, J, Grim, JE, Harper, JW, Eisenman, RN, Clurman, BE. 2004. The Fbw7 tumor suppressor regulates glycogen synthase kinase 3 phosphorylation-dependent c-Myc protein degradation. Proc. Natl. Acad. Sci. USA 101:9085-9090. doi: 10.1073/pnas.0402770101.

Weng, AP, et al. 2006. c-Myc is an important direct target of Notch1 in T-cell acute lymphoblastic leukemia/lymphoma. Genes Dev. 20:2096-2109. doi: 10.1101/gad.1450406.

Wilson, $\mathrm{FH}$, et al. 2001. Human hypertension caused by mutations in WNK kinases. Science 293:1107-1112. doi: 10.1126/science.1062844.

Xie, J, Wu, T, Xu, K, Huang, IK, Cleaver, O, Huang, CL. 2009. Endothelial-specific expression of WNK1 kinase is essential for angiogenesis and heart development in mice. Am. J. Path. 175:1315-1327. doi: 10.2353/ajpath.2009.090094. 
bioRxiv preprint doi: https://doi.org/10.1101/2020.06.11.147017; this version posted June 12, 2020. The copyright holder for this preprint (which was not certified by peer review) is the author/funder, who has granted bioRxiv a license to display the preprint in perpetuity. It is made available under aCC-BY 4.0 International license.

Köchl et al

Yada, M, et al. 2004. Phosphorylation-dependent degradation of c-Myc is mediated by the F-box protein Fbw7. EMBO J. 23:2116-2125. doi: 10.1038/sj.emboj.7600217.

Yamasaki, S, Saito, T. 2007. Molecular basis for pre-TCR-mediated autonomous signaling. Trends Immunol. 28:39-43. doi: 10.1016/j.it.2006.11.006. 


\section{Figure Legends}

\section{Figure 1. Essential role for WNK1 in thymocyte development}

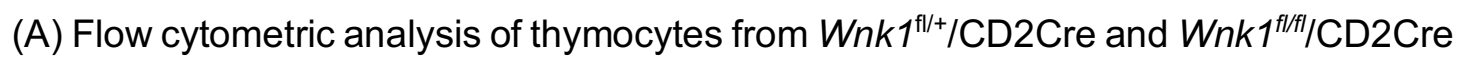
mice showing double negative (DN, Thy $1.2^{+}$Lineage $\left.{ }^{-}\right)$thymocytes subdivided into DN1 $\left(\mathrm{CD} 44^{+} \mathrm{CD} 25^{-}\right), \mathrm{DN} 2+\mathrm{DN} 3\left(\mathrm{CD}^{\circ} 5^{+}\right)$, and DN4 (CD44 CD25) subsets, immature single positive (ISP, CD4 $\left.{ }^{-} \mathrm{CD} 8^{+} \mathrm{TCR} \beta^{-}\right)$, double positive (DP, $\left.\mathrm{CD} 4^{+} \mathrm{CD} 8^{+}\right), \mathrm{CD} 4^{+}$single positive (4SP, $\left.\mathrm{CD}^{+} \mathrm{CD} 8^{-}\right)$and $\mathrm{CD}^{+}$single positive (8SP, CD4 $\left.{ }^{-} \mathrm{CD} 8^{+} \mathrm{TCR} \beta^{+}\right)$thymocytes. Numbers show \% of cells falling into each gate. (B) Mean \pm SEM number of thymocytes at each developmental stage defined using the gates in A. (C) Mean \pm SEM percentage of cells in each thymocyte population in $W n k 1^{f / / f / f} / C D 2 C r e$ animals normalized to Wnk $1^{\mathrm{fl} / \mathrm{t}} / \mathrm{CD} 2 \mathrm{Cre}$ controls (set to $100 \%$ ). (D) Mean \pm SEM Wnk1 mRNA levels in thymic subsets from $W n k 1^{f /+} / C D 2 C r e$ and $W n k 1^{f / f / f} / C D 2 C r e$ mice, normalized to Wnk $1^{\mathrm{fl} / \mathrm{+}} / \mathrm{CD} 2 \mathrm{Cre}$ controls (set to $100 \%$ ) measured by Q-PCR from exon 1 to exon 2. CD44 levels were used to separate DN2 $\left(\mathrm{CD} 44^{+}\right)$and DN3 (CD44 $)$thymocytes. (E) Flow cytometric analysis of $\operatorname{Rag} 1^{-/-}$radiation chimeras reconstituted with bone marrow from $W n k 1^{\mathrm{fl} / \mathrm{t}} / \mathrm{RCE}$ and $W n k 1^{\mathrm{fl} / \mathrm{D} 368 \mathrm{~A}} / \mathrm{RCE}$ mice, treated with tamoxifen and analyzed 7 d later showing gating for thymocyte subsets as in A, with double negative (DN, Thy $1.2^{+}$Lineage $^{-}$) thymocytes pre-gated on $\mathrm{CD}^{-}{ }^{-C D} 8^{-}$cells. (F) Mean $\pm S E M$ number of cells in thymocyte subsets of $\operatorname{Rag} 1^{1 /}$ chimeras as in E. ${ }^{*} 0.01<P<0.05,{ }^{* *} 0.001<P$ $<0.01$, and ${ }^{* *} P<0.001$. Significance calculated by Mann-Whitney test. Sample sizes: five $W n k 1^{\mathrm{fl} / \mathrm{t}} / \mathrm{CD} 2 \mathrm{Cre}$ and six $W n k 1^{f / f t /} / \mathrm{CD} 2 \mathrm{Cre}$ mice $(\mathrm{B}, \mathrm{C})$, seven (D), and six (F) of each genotype. Data are from one of two experiments $(A, E)$ or pooled from two (B-D, F).

Figure 2. WNK1 is required for thymocytes to develop past the pre-TCR checkpoint 
(A) Left: Flow cytometric analysis of thymocytes from $W n k 1^{\mathrm{fl} / \mathrm{t}} / \mathrm{CD} 2 \mathrm{Cre}$ and

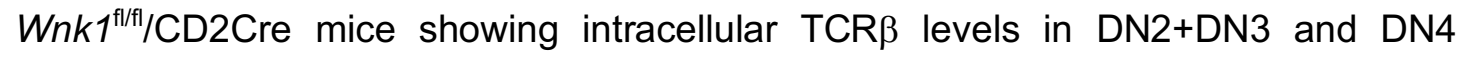
subsets. Numbers indicate the percentage of $\mathrm{TCR}^{+}$cells. Right: Mean \pm SEM percentage of DN2+DN3 and DN4 cells that are intracellular TCR $\beta^{+}$. (B) Mean \pm SEM of $\mathrm{CD} 3 \varepsilon$ or pre-T $\alpha$ surface levels measured as mean fluorescence intensity (MFI) in flow cytometry of DN2+DN3 and DN4 thymocytes from $W n k 1^{\mathrm{fl} /+} / \mathrm{CD} 2 \mathrm{Cre}$ and Wnk $1^{\text {ft/fl/ } / C D 2 C r e ~ m i c e . ~(C) ~ L e f t: ~ f l o w ~ c y t o m e t r i c ~ a n a l y s i s ~ o f ~ C D 4 ~ a n d ~ C D 8 ~ l e v e l s ~ o n ~}$

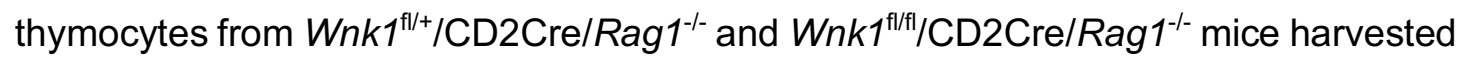
$4 \mathrm{~d}$ after intraperitoneal injection with PBS or anti-CD3 $\varepsilon$ antibody. Gate indicates DP thymocytes and number shows percentage of cells in the gate. Right: mean \pm SEM number of DP thymocytes defined using the gates on the left. * $0.01 P<0.05$, and ** $P<0.01$. Significance calculated by Mann-Whitney test. Sample sizes: six of each

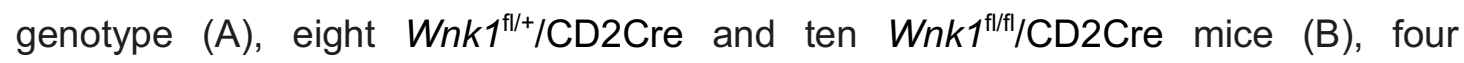

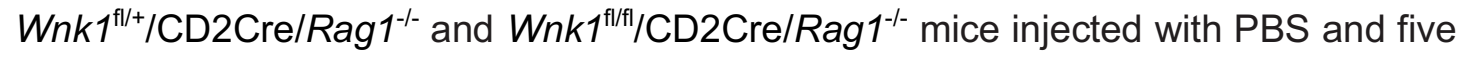

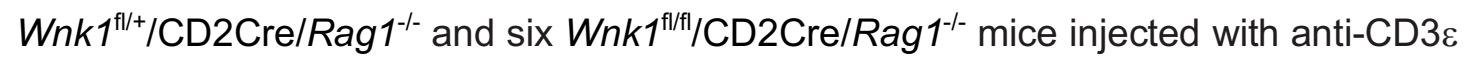
(C). Data are pooled from two experiments (A-C).

Figure 3. RNAseq of WNK1-deficient thymocytes reveals significant changes in

\section{5 distinct processes}

(A) Thymi were harvested from $W n k 1^{\mathrm{fl} /+} / \mathrm{CD} 2 \mathrm{Cre} / \mathrm{Rag} 1^{1 /-}$ and $W n k 1^{\mathrm{fl} /+} / \mathrm{CD} 2 \mathrm{Cre} / \mathrm{Rag} 1^{-/-}$ mice that were either untreated $(0 \mathrm{~h})$ or had been injected with anti-CD3 $\varepsilon$ antibody 3 , 24 or $48 \mathrm{~h}$ earlier. DN3+DN4 thymocytes were sorted, RNA purified and analyzed by RNAseq, results of which are shown in C-E. (B) Flow cytometric analysis of DN thymocytes from the experiment described in A. Gates indicate cells (Thy1.2+ CD44) that were sorted for further RNAseq analysis. (C) Principal component analysis using expression of all normalized genes for all samples from the experiment described in A. (D) $\log _{2}$ fold changes and total number of statistically significant differentially 
expressed genes (DEGs) in samples from Wnk1 $1^{\mathrm{flff} / \mathrm{CD} 2 \mathrm{Cre} / \mathrm{Rag} 1^{-1-}}$ (KO) mice compared to $W n k 1^{f /+} / \mathrm{CD} 2 \mathrm{Cre} / \operatorname{Rag}^{-/-}(\mathrm{HET})$ mice at each time point (Tables S2, S3). (E) Metacore process analysis of DEGs. Selected processes and their $P$-values are shown at each time point; graph on left shows the lowest $P$-value for each process from any of the 4 time points. Red bars indicate time point with the lowest $P$-values for each process (Minimal). Ratios indicate the number of DEGs at each time point over the number of all genes in the indicated processes. Significance calculated by Wald's test (D) and Hypergeometric test (E). Sample sizes: three Wnk $1^{\mathrm{fl} /+} / \mathrm{CD} 2 \mathrm{Cre}$ Rag $1^{-/-}$and

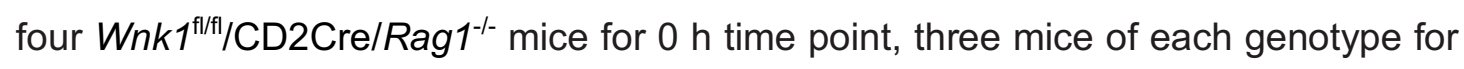
all other time points; data are from one experiment.

Figure 4. WNK1 deficiency does not perturb early pre-TCR-induced signaling and protein translation

(A-D) Analysis of RNAseq experiment described in Figure 3A. (A) Heatmap and hierarchical clustering of selected genes from the TCR signaling signature at $0 \mathrm{~h}$ in $W n k 1^{\mathrm{fl} / \mathrm{+}} / \mathrm{CD} 2 \mathrm{Cre} / \operatorname{Rag}^{-/-}$and $W n k 1^{\mathrm{fl} / \mathrm{+}} / \mathrm{CD} 2 \mathrm{Cre} / \operatorname{Rag}^{-1^{--}}$mice. Red and blue colors indicate increased or decreased expression of indicated genes relative to the mean expression of each row using normalized $\log _{2}$ expression values. (B) Mean \pm SEM expression of selected genes; TPM, transcripts per million reads. (C) Mean \pm SEM surface levels of CD25 on CD44- thymocytes analyzed as in Figure 3B. (D) Heatmap and hierarchical clustering of selected genes from the translation signature at $0 \mathrm{~h}$. (E) Histograms showing levels of phospho-S6 (pS6) in CD44- DN thymocytes from

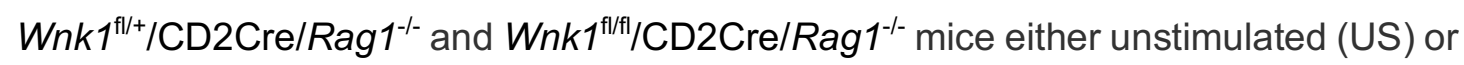

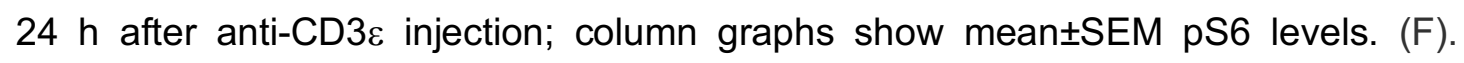
Histograms showing rate of protein synthesis measured by O-propargyl-puromycin (OPP) incorporation in CD44- DN thymocytes from $W n k 1^{f / /+} / C D 2 C r e / R a g 1^{1 /-}$ and

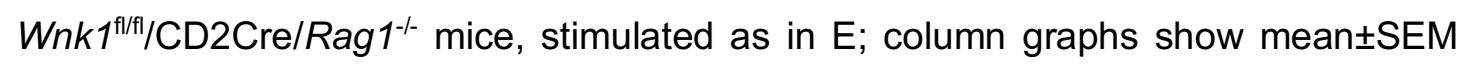
rate of protein synthesis. ${ }^{*} 0.01<P<0.05,{ }^{* *} 0.001<P<0.01,{ }^{* * *} 0.0001<P<0.001$, 
${ }^{* * * *} P<0.0001$. Significance displayed in $(B)$ is from the analysis of the RNAseq data and was calculated by the Wald test (Table S3). Significance calculated by MannWhitney test $(\mathrm{C}, \mathrm{E}, \mathrm{F})$. Sample sizes: three $W n k 1^{\mathrm{fl} /+} / \mathrm{CD} 2 \mathrm{Cre} R \mathrm{Rag} 1^{1 /-}$ and four $W n k 1^{\mathrm{fl} / \mathrm{fl}} / \mathrm{CD} 2 \mathrm{Cre} / \operatorname{Rag}^{1 /-}$ mice for $0 \mathrm{~h}$ time point and three mice of each genotype for all other time points $(A-D)$, five $(E)$ and four $(F)$ of each genotype. Data are from one experiment (A-D) or pooled from two (E, F).

\section{Figure 5. WNK1 regulates thymocyte migration and adhesion}

(A) Heatmap and hierarchical clustering of selected genes from the adhesion signature

at 24 and $48 \mathrm{~h}$ after injection of anti-CD3 $\varepsilon$ into $W n k 1^{\mathrm{fl} /+} / \mathrm{CD} 2 \mathrm{Cre} / \mathrm{Rag} 1^{-/-}$and

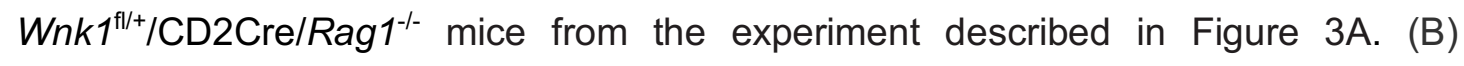
Mean \pm SEM LFA1 and CXCR4 surface levels in DN2+DN3 and DN4 thymocytes, pregated on double negative $\left(\mathrm{TCR} \beta^{-}\right.$, Thy $1.2^{+}$, Lineage $\left.{ }^{-}\right)$thymocytes, from

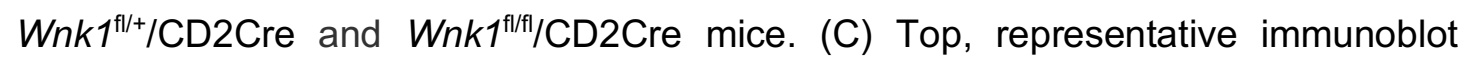
analysis of phosphorylated OXSR1 (pOXSR1) and ERK2 in total Rag $1^{-1-}$ thymocytes incubated with DMSO or WNK463 and stimulated for 0 or 1 min with CXCL12. Below, quantification of pOXSR1 normalized to the abundance of ERK2. (D) Binding of soluble ICAM1 complexes to mouse DN2+DN3 thymocytes from $W n k 1^{\mathrm{fl} /+} / \mathrm{CD} 2 \mathrm{Cre} / \mathrm{Rag}^{-{ }^{-/}}$and $W n k 1^{f / / f l} / \mathrm{CD} 2 \mathrm{Cre} / \operatorname{Rag}^{1 /-}$ mice in response to treatment for various times with anti$\mathrm{CD} 3 \varepsilon, \mathrm{CXCL} 12$ or $\mathrm{MnCl}_{2}$. (E) Migration of mouse DN2+DN3 thymocytes from the top chamber to the bottom chamber of a Transwell plate in the presence $(+)$ or absence (-) of CXCL12. (F) Left: representative images of frozen thymus sections from lethally irradiated B6.SJL mice, reconstituted with a 80:20 mixture of bone marrow from B6.SJL

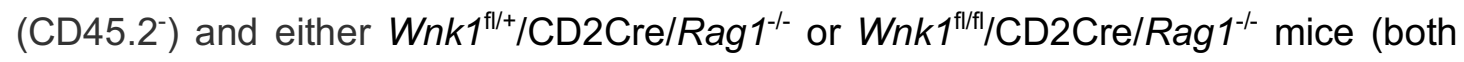
CD45.2 ${ }^{+}$), stained with antibodies to the indicated antigens, as well as antibodies to CD11b and CD11c (not shown). Right: distribution of $W n k 1^{\mathrm{fl} /+} / \mathrm{CD} 2 \mathrm{Cre} / \mathrm{Rag} 1^{-/-}$or

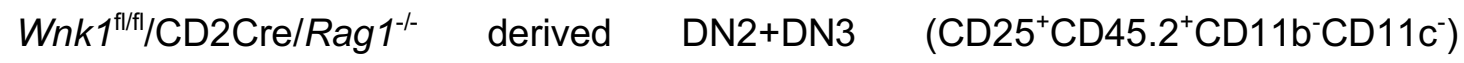


thymocytes between the subcapsular zone (SCZ), cortex and cortico-medullary junction (CMJ) as defined by the ERTR5 staining for medullary epithelial cells. (G) Left: flow cytometric analysis of DN2+DN3 thymocytes from $W n k 1^{\mathrm{fl} /+} / \mathrm{CD} 2 \mathrm{Cre}$ and

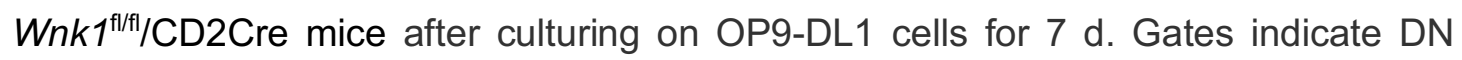

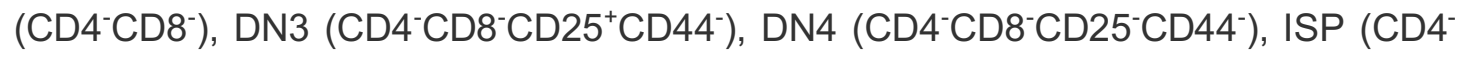
$\left.\mathrm{CD}^{+}{ }^{+} \mathrm{TCR} \beta^{-}\right) \mathrm{DP}\left(\mathrm{CD} 4^{+} \mathrm{CD} 8^{+}\right), 4 \mathrm{SP}\left(\mathrm{CD} 4^{+} \mathrm{CD} 8^{-}\right)$and $8 \mathrm{SP}\left(\mathrm{CD} 4^{-} \mathrm{CD} 8^{+} \mathrm{TCR} \beta^{+}\right)$cells. Right: mean \pm SEM number of all cells and number of DP cells recovered after $7 \mathrm{~d}$. Dashed line indicates number of cells seeded into the cultures on day 0 . ${ }^{*} 0.01<P<$ $0.05,{ }^{* *} 0.001<P<0.01,{ }^{* * *} 0.0001<P<0.001,{ }^{* * * *} P<0.0001$. Significance calculated by Mann-Whitney test (B-G). Sample sizes: three of each genotype (A),

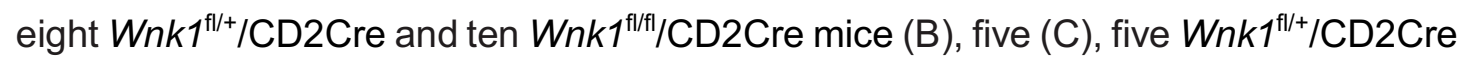
and seven $W n k 1^{\mathrm{fl} / \mathrm{fl}} / \mathrm{CD} 2 \mathrm{Cre}$ mice for the anti-CD3$\varepsilon^{-}$and $\mathrm{MnCl}_{2}$-induced adhesion assays and five and six for the CXCL12-induced adhesion assays (D), six (E, G), and four $(F)$ of each genotype. Data are from one experiment $(A)$ or pooled from two (B, D$\mathrm{G})$ or five (C) experiments.

\section{Figure 6. WNK1 controls entry into S-phase.}

(A-C) Analysis of RNAseq experiment described in Figure 3A. (A) Heatmap and hierarchical clustering of selected genes from the cell cycle signature at $24 \mathrm{~h}$ after injection of anti-CD3e. (B) Canonical cell cycle signaling diagram for the transition from $\mathrm{G} 1$ to $\mathrm{S}$ phase. Genes colored in blue are downregulated at the $24 \mathrm{~h}$ time point in samples from $W n k 1^{\mathrm{f} / / \mathrm{l} /} / \mathrm{CD} 2 \mathrm{Cre} / \mathrm{Rag} 1^{-/-}$mice compared to $W n k 1^{\mathrm{fl} /+} / \mathrm{CD} 2 \mathrm{Cre} / \mathrm{Rag} 1^{-/-}$ mice, genes in red are upregulated. Vertical arrows indicate genes induced or repressed by MYC (Bretones et al., 2015) (C) Mean \pm SEM expression of up- or downregulated genes displayed in B. (D) Left: flow cytometric analysis of DNA content

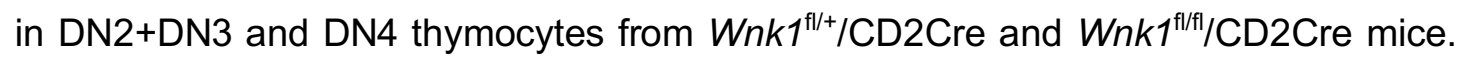
Gates show percentage of cells containing more than the diploid amount of DNA (S, 
G2 and M phases of cell cycle). Right: mean \pm SEM percentage of cells in S/G2/M phases of the cell cycle based on gate shown on histograms. (E) Mean \pm SEM forward scatter, a measure of cell size, measured by flow cytometry of DN2+3 and DN4

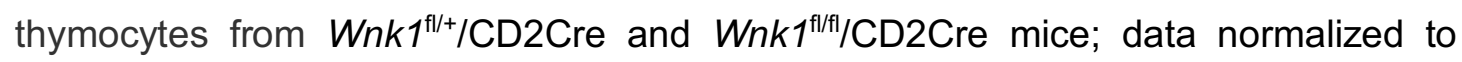
Wnk $1^{\mathrm{fl} /+} / \mathrm{CD} 2 \mathrm{Cre} \mathrm{DN} 2+3$ cells (set to $100 \%$ ). ${ }^{*} 0.01<P<0.05,{ }^{* *} 0.001<P<0.01$, *** $0.0001<P<0.001,{ }^{* * *} P<0.0001$. Significance was calculated by the Wald test for RNAseq data $(C)$ or by the Mann-Whitney test $(D, E)$. Sample sizes: three $(A, C)$ or five (D) of each genotype and nine $W n k 1^{f / /+} / C D 2 C r e$ and seven $W n k 1^{f / l f l} / C D 2 C r e$ mice (E). Data are from one experiment $(A, C)$, or pooled from two (D, E).

Figure 7. WNK1 is required for pre-TCR induced post-transcriptional regulation of MYC

(A, B) Analysis of RNAseq experiment described in Figure 3A. (A) Table shows top 6 transcription factors whose known target genes were most enriched among all significant DEGs at $24 \mathrm{~h}$ or among only cell cycle genes at $24 \mathrm{~h}$; results from Metacore transcription factor analysis. (B) Mean \pm SEM expression of mRNAs for transcription factors identified in A. Note that graphs of E2f1, E2f2, E2f4 and E2f7 are duplicated from Figure 6C. (C) Left: flow cytometric analysis of MYC levels in DN2+DN3 thymocytes from $W n k 1^{\mathrm{fl} /+} / \mathrm{CD} 2 \mathrm{Cre} / \operatorname{Rag} 1^{1^{-/}}$and $W n k 1^{\mathrm{fl} / \mathrm{fl}} / \mathrm{CD} 2 \mathrm{Cre} / \mathrm{Rag} 1^{-/-}$mice either untreated (UT) or $48 \mathrm{~h}$ after injection with anti-CD3ع. Right: mean \pm SEM levels of MYC protein in DN1 and DN2+DN3 thymic subsets normalized to levels in DN2+DN3 cells from injected $W n k 1^{\mathrm{fl} /+} / \mathrm{CD} 2 \mathrm{Cre} / \operatorname{Rag} 1^{-/-}$control mice (set to 100\%). (D) Left: flow cytometric analysis of MYC levels in DN2+DN3 or DN4 thymocytes from $W n k 1^{\mathrm{fl} / \mathrm{+}} / \mathrm{CD} 2 \mathrm{Cre}$ and $W n k 1^{\mathrm{fl/fl} / C D 2 C r e}$ mice. Right: mean \pm SEM levels of MYC in DN2+DN3 or DN4 thymocytes. MFI, mean fluorescence intensity. ns, not significant; * $0.01<P<0.05,{ }^{* *} 0.001<P<0.01,{ }^{* * *} P<0.001$. Significance calculated by hypergeometric test $(A)$, the Wald test $(B)$, or the Mann-Whitney test $(C, D)$. Sample

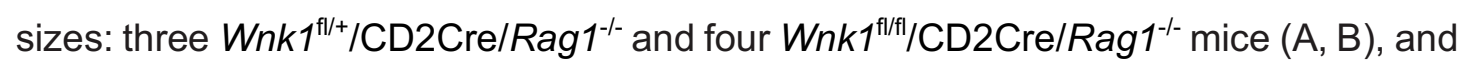


five (C) or four (D) of each genotype. Data are from one experiment (A, B, D), or pooled from three $(C)$.

Figure 8. OXSR1 and STK39 are required for pre-TCR induced proliferation and regulation of MYC

(A-C) Mean \pm SEM number of thymocytes at each developmental stage in Stk39//+ and Stk39 $9^{\text {T243A/T243A }}$ mice $(\mathrm{A})$ or in $R a g 1^{1--}$ radiation chimeras reconstituted with fetal liver cells from $\mathrm{Oxsr}^{+/+}$and Oxsr1 ${ }^{\text {T185A/T185A }}$ embryos (B) or $\mathrm{Oxsr}^{+/+} \mathrm{Stk} 39^{+/+} / \mathrm{RCE}$,

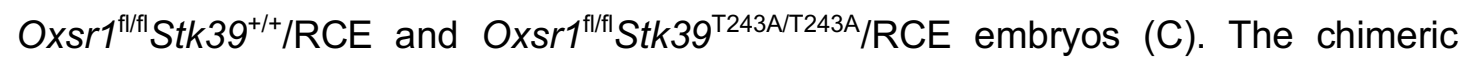
mice in $\mathrm{C}$ were analyzed $7 \mathrm{~d}$ after treatment with tamoxifen. Thymocyte subsets were identified by flow cytometry as shown in Figure 1A, E. (D) Left: flow cytometric analysis of DNA content in DN4 thymocytes from Rag $1^{1--}$ radiation chimeras reconstituted with fetal liver cells of the indicated genotypes. Gates show percentage of cells containing more than the diploid amount of DNA (S, G2 and M phases of cell cycle). Right: mean $\pm S E M$ percentage of cells in S/G2/M phases of the cell cycle based on gate shown on histograms. (E) Left: flow cytometric analysis of MYC levels in DN4 thymocytes from $R a g 1^{-/-}$radiation chimeras reconstituted with fetal liver cells of the indicated genotypes. Right: mean \pm SEM levels of MYC in DN4 thymocytes. (F) Mean \pm SEM number of thymocytes at each developmental stage in $R a g 1^{-1-}$ radiation chimeras reconstituted with liver cells from S/c12a2 $2^{+/+}$and S/c12a $2^{-/-}$embryos. (G) Mean \pm SEM percentage of cells in each thymocyte population in chimeras reconstituted with $S / c 12 a 2^{-/-}$fetal liver normalized to S/c12a $2^{+/+}$control chimeras (set to $100 \%$ ). ${ }^{*} 0.01<P<0.05$, ${ }^{* *} 0.001<P<0.01$, and ${ }^{* * *} P<0.001$. Significance calculated by Mann-Whitney test. Sample sizes: six (A, F, G) or eight (B) of each

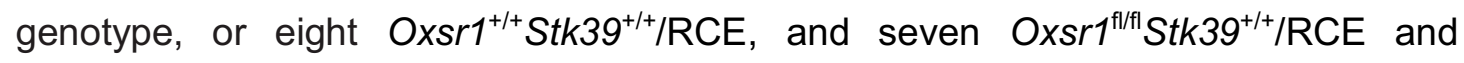
Oxsr1 $1^{\mathrm{f} / \mathrm{l} I} S t k 39^{\mathrm{T} 243 \mathrm{~A} / \mathrm{T} 243 \mathrm{~A}} / \mathrm{RCE}$ mice (C-E). In all cases, data are pooled from two independent experiments. 
Köchl et al

\section{Supplementary Data}

Supplementary Table 1. RNAseq analysis of control and WNK1-deficient DN3

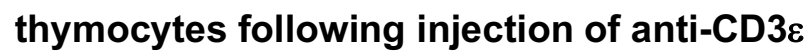

Analysis of RNAseq experiment described in Figure 3A, showing expression of all genes measured in TPM at all time points.

Supplementary Table 2. Differential gene expression in control and WNK1deficient DN3 thymocytes following injection of anti-CD3ع

Analysis of RNAseq experiment described in Figure 3A, showing differential gene expression analysis with DESeq2, taking into account all genes.

Supplementary Table 3. Significant differential gene expression in control and WNK1-deficient DN3 thymocytes following injection of anti-CD3 $\varepsilon$

Analysis of RNAseq experiment described in Figure 3A, showing differential gene expression analysis with DESeq2 as in Supplementary Table 2 but showing only genes that were statistically significantly differentially expressed (padj $\leq 0.05$ ) and had an average expression value of TPM $>3$ over all conditions.

Supplementary Figure 1. Expression of genes encoding WNK pathway proteins Mean \pm SEM expression of genes in the WNK1 pathway in the indicated thymocyte subsets, re-analyzed from previously published data (Hu et al., 2013).

Supplementary Figure 2. WNK1 is not required for progression of DN3 thymocytes into late $\mathbf{G 1}$

Analysis of RNAseq experiment described in Figure $3 A$, showing mean \pm SEM expression of selected genes associated with progression from the early to late G1 
phase of the cell cycle at $0 \mathrm{~h}$ and $3 \mathrm{~h}$ following injection of anti-CD3E. ${ }^{*} 0.01<P<0.05$.

Significance displayed is from the analysis of the RNAseq data and was calculated by

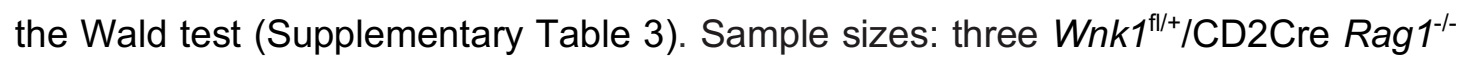
and four $W n k 1^{f / / f l} / C D 2 C r e / R a g 1^{-1-}$ mice for $0 \mathrm{~h}$ time point and three mice of each genotype for $3 \mathrm{~h}$ time point. Data are from one experiment.

Supplementary Figure 3. Expression of anti-apoptotic genes in the absence of WNK1

(A) Analysis of RNAseq experiment described in Figure $3 \mathrm{~A}$, showing mean \pm SEM expression of anti-apoptotic genes. No expression was detected of the Bc/2a1 genes. (B) Graph shows mean \pm SEM \% of DN2 and DN3 (DN2+DN3) or DN4 thymocytes of the indicated genotypes that stained positively for active Caspase 3; there was no statistically significant difference in the level of active Caspase 3 between genotypes. ${ }^{*} 0.01<P<0.05,{ }^{* *} 0.001<P<0.01$, and ${ }^{* * *} P<0.0001$. Significance was calculated by the Wald test (A, Table S3) or by the Mann-Whitney test (B). Sample sizes: three

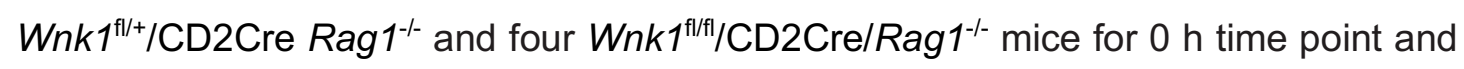
three mice of each genotype for all other time points $(A)$, or 6 of each genotype $(B)$. Data are from one experiment $(A)$ or pooled from two $(B)$. 
bioRxiv preprint doi: https://doi.org/10.1101/2020.06.11.147017; this version posted June 12, 2020. The copyright holder for this preprint (which was not certified by peer review) is the author/funder, who has granted bioRxiv a license to display the preprint in perpetuity. It is Figure 1 made available under aCC-BY 4.0 International license.

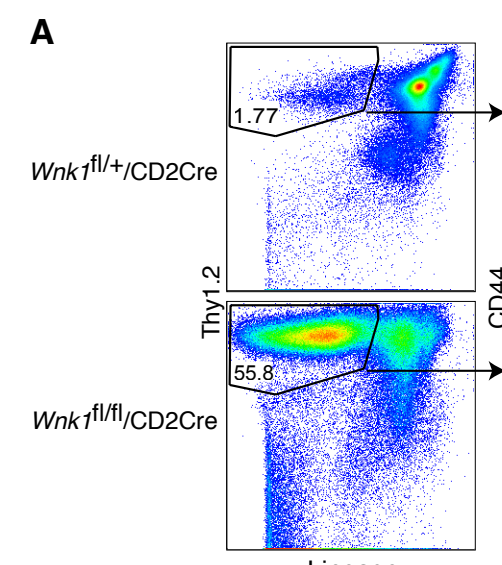

Lineage

B

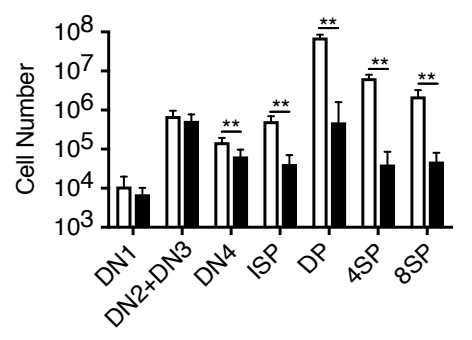

C

E

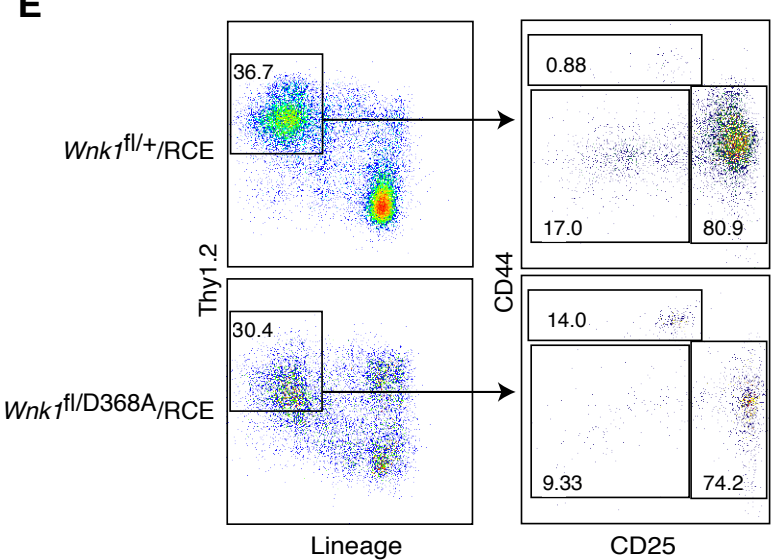

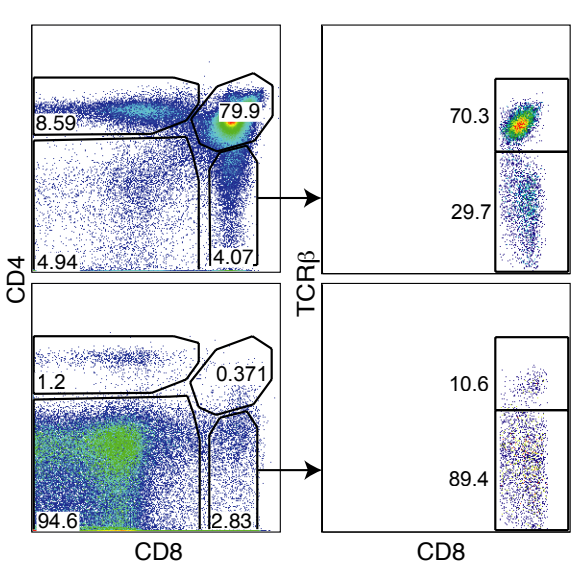

D $\square$ Wnk1 $1^{\mathrm{fl} /} / \mathrm{CD} 2 \mathrm{Cre}$ Wnk $1^{\mathrm{fl} / \mathrm{fl} / \mathrm{CD} 2 \mathrm{Cre}}$
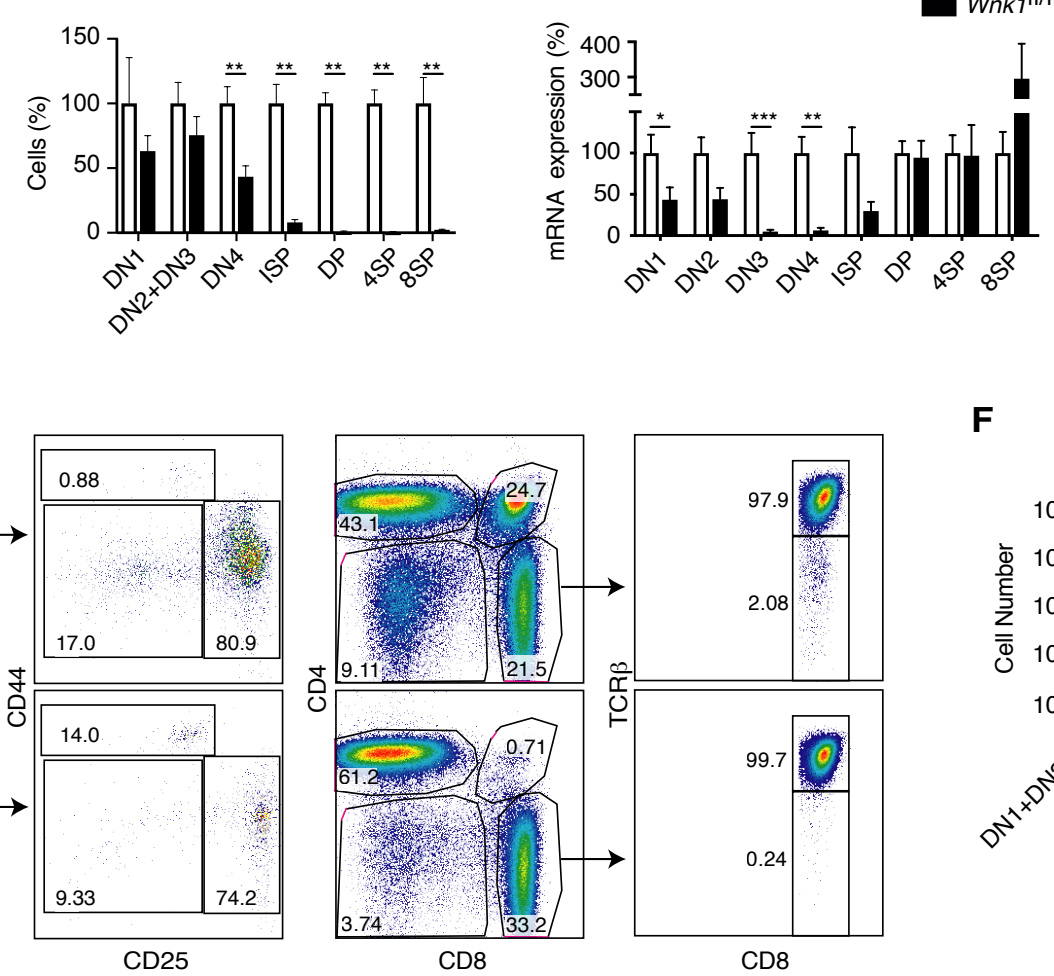

$\mathbf{F}$

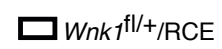
Wnk $1^{\mathrm{fl} / \mathrm{D} 368 \mathrm{~A}} / \mathrm{RCE}$

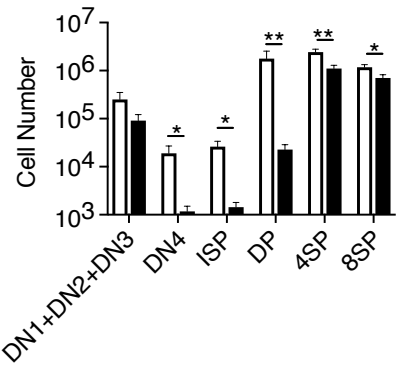


bioRxiv preprint doi: https://doi.org/10.1101/2020.06.11.147017; this version posted June 12, 2020. The copyright holder for this preprint wich was notertified by peer review) is the author/funder, who has granted bioRxiv a license to display the preprint in perpetuity. It is Figure 2 made available under aCC-BY 4.0 International license.

A

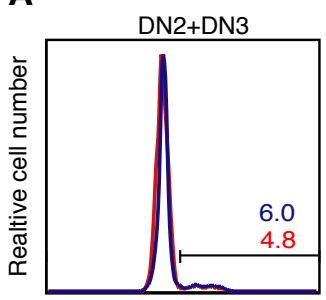

intracellular TCR $\beta$
DN4

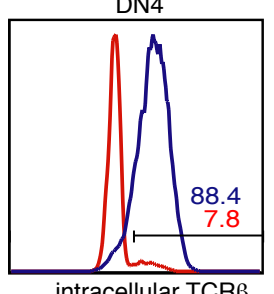

intracellular TCR $\beta$

Wnk $7^{\text {fl } / /+} / \mathrm{CD} 2 \mathrm{Cre}$

Wnk fl/fl/CD2Cre $^{\mathrm{f} / \mathrm{CD}}$

B

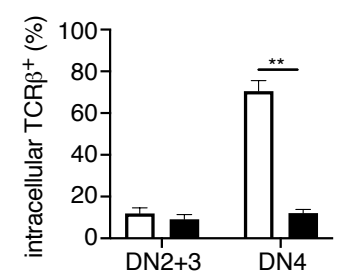

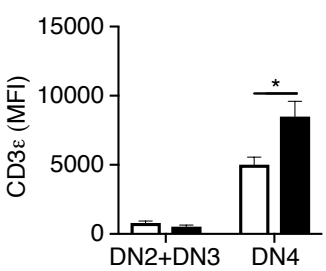

$\square W n k 1^{\mathrm{fl} / \mathrm{+} / \mathrm{CD} 2 \mathrm{Cre}}$ Wnk $1^{f l / f l} / C D 2 C r e$

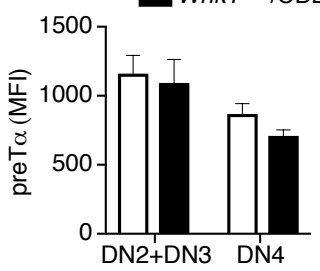

C

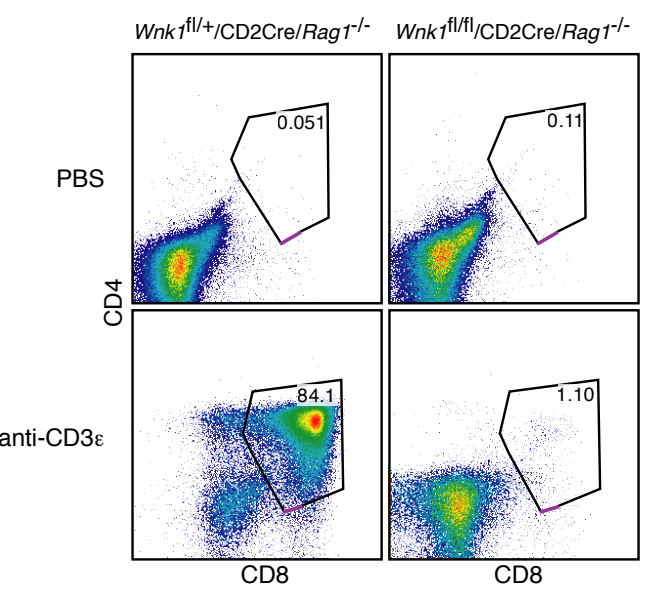

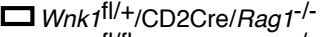

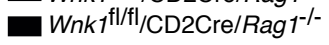

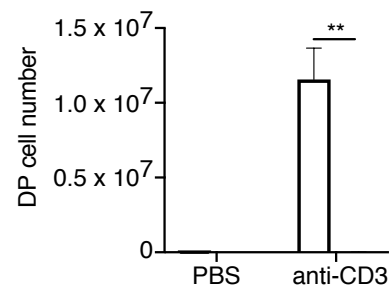


bioRxiv preprint doi: https://doi.org/10.1101/2020.06.11.147017; this version posted June 12, 2020. The copyright holder for this preprint (which was not certified by peer review) is the author/funder, who has granted bioRxiv a license to display the preprint in perpetuity. It is Figure 3 made available under aCC-BY 4.0 International license.

A

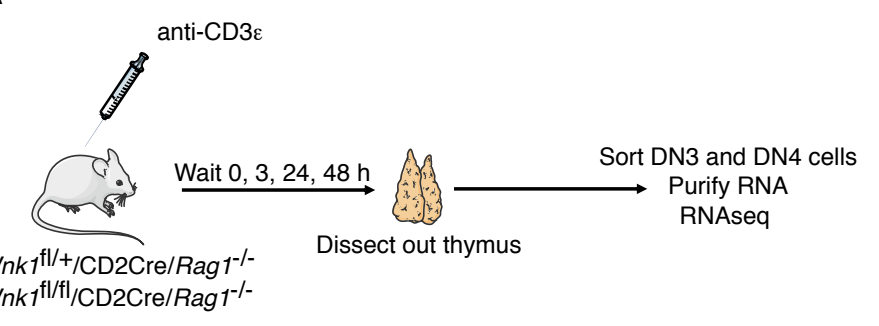

C $\bullet W_{n k} k_{1}^{f l / / / C D 2 C r e / R a g} 1^{-1-}$

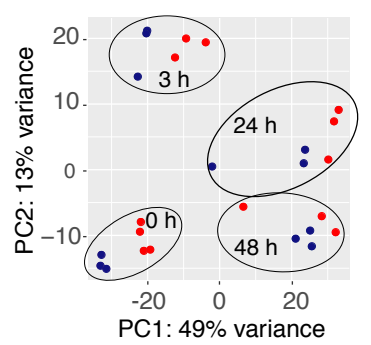

$\begin{array}{ccc}-20 & 0 & 20 \\ \text { PC1: } & 49 \% & \text { variance }\end{array}$
D

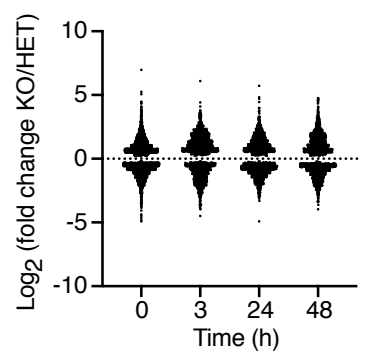

\begin{tabular}{ll|l|l|l|} 
Genes UP $\quad 1591$ & 912 & 1033 & 1001 \\
\hline
\end{tabular}

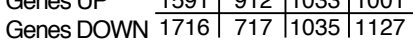

B

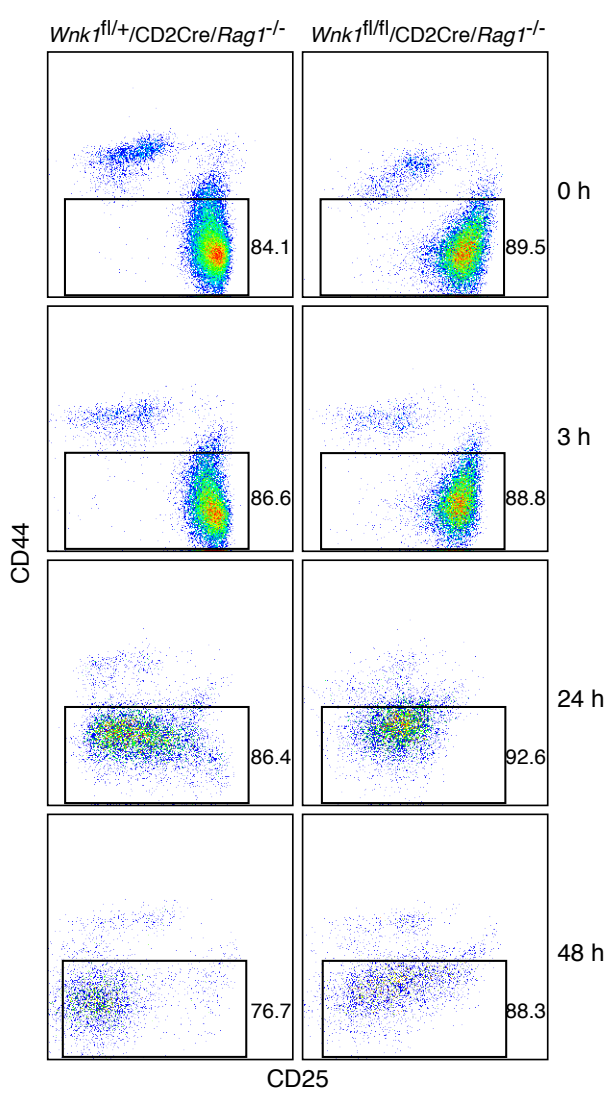

E

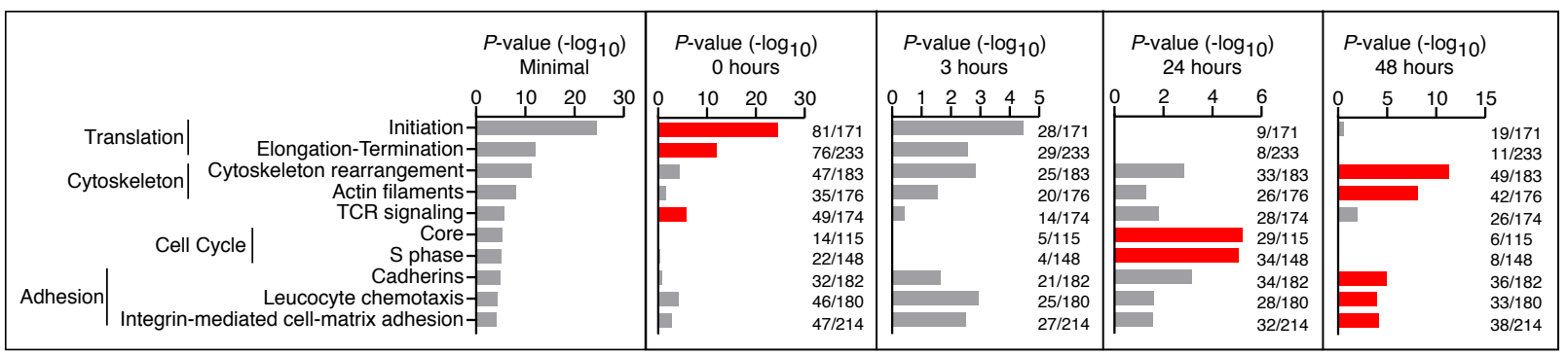


bioRxiv preprint doi: https://doi.org/10.1101/2020.06.11.147017; this version posted June 12, 2020. The copyright holder for this preprint (which was not certified by peer review) is the author/funder, who has granted bioRxiv a license to display the preprint in perpetuity. It is Figure 4

A made available under aCC-BY 4.0 International license.
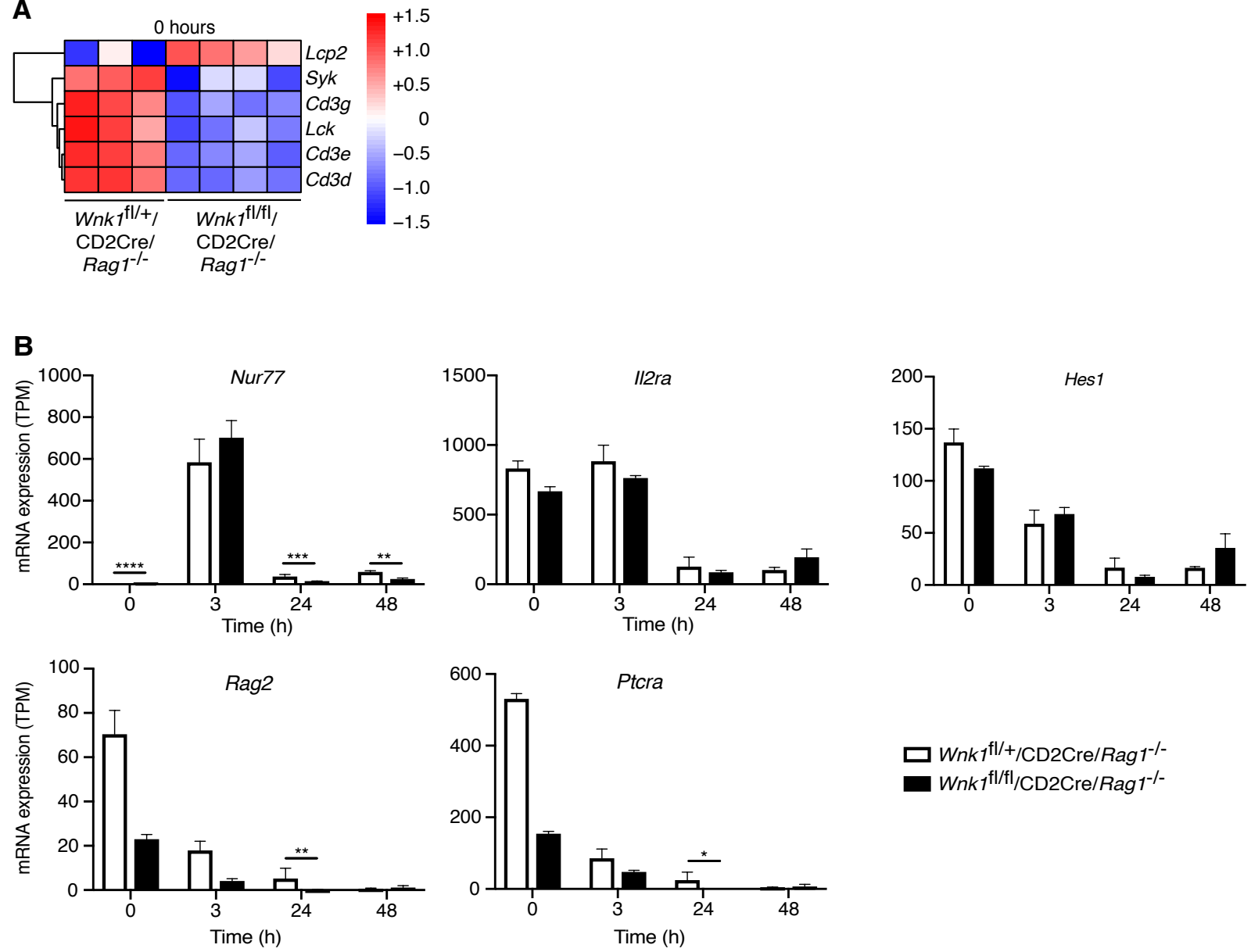

Wnk $1^{\mathrm{fl} /+} / \mathrm{CD} 2 \mathrm{Cre} /$ Rag $_{1} /-$

C

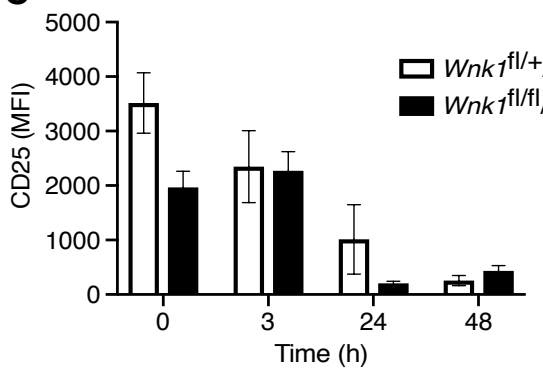

$\mathbf{E}$

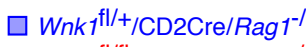
$\square$ Wnk $1^{f / / f l} / \mathrm{CD} 2 \mathrm{Cre} /$ Rag $^{-/-}$

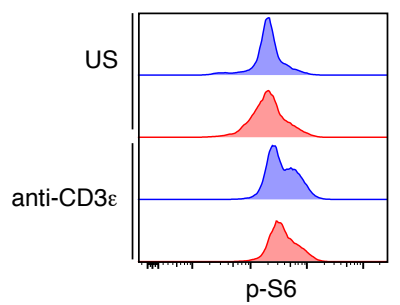

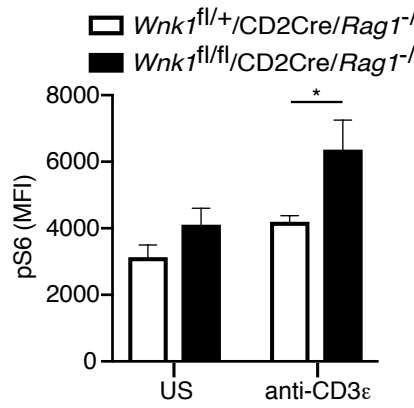

D

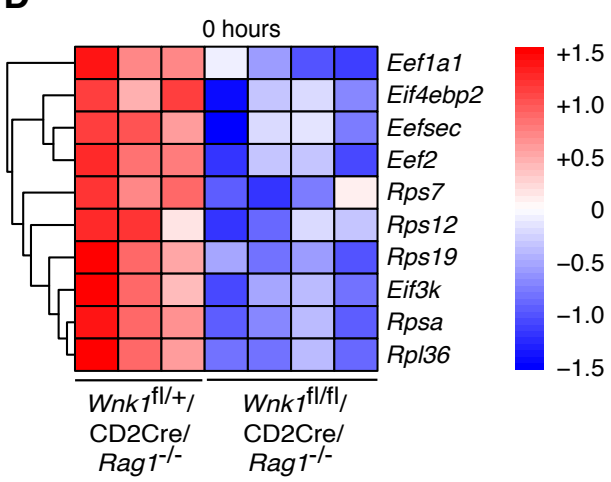

$\mathbf{F}$

$\square W n k 1^{\mathrm{fl} /+} / \mathrm{CD} 2 \mathrm{Cre} /$ Rag $^{-/-}$ $\square W_{n k} 1^{f / / f l} / \mathrm{CD} 2 \mathrm{Cre} /$ Rag $^{-/-}$

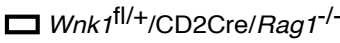

- Wnk $1^{\mathrm{fl} / \mathrm{fl} / \mathrm{CD} 2 \mathrm{Cre} / \text { Rag } 1^{-/-}}$
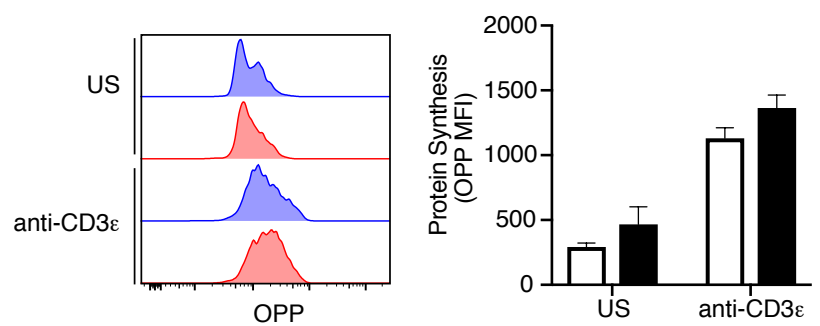
bioRxiv preprint doi: https://doi.org/10.1101/2020.06.11.147017; this version posted June 12, 2020. The copyright holder for this preprint (which was not certified by peer review) is the author/funder, who has granted bioRxiv a license to display the preprint in perpetuity. It is Figure 5

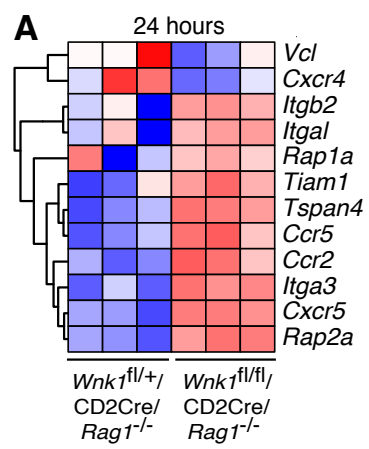

C

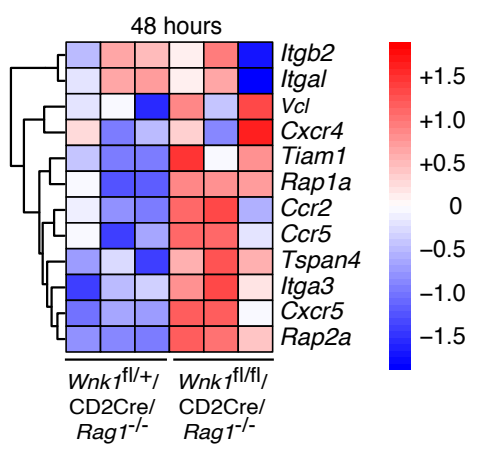

D
B

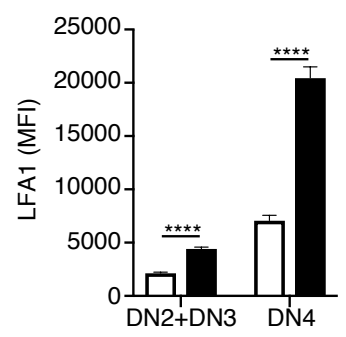

口Wnk $t^{\mathrm{fl} / /} / \mathrm{CD} 2 \mathrm{Cre}$ - $W n k t^{\mathrm{fl} / \mathrm{fl} / \mathrm{CD} 2 \mathrm{Cre}}$

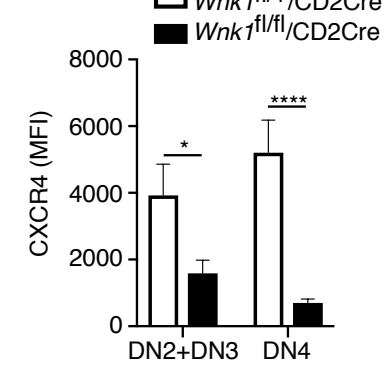

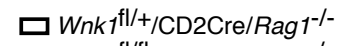
- $W n k 1^{f l / f l} / \mathrm{CD} 2 \mathrm{Cre} /$ Rag $1^{-/-}$
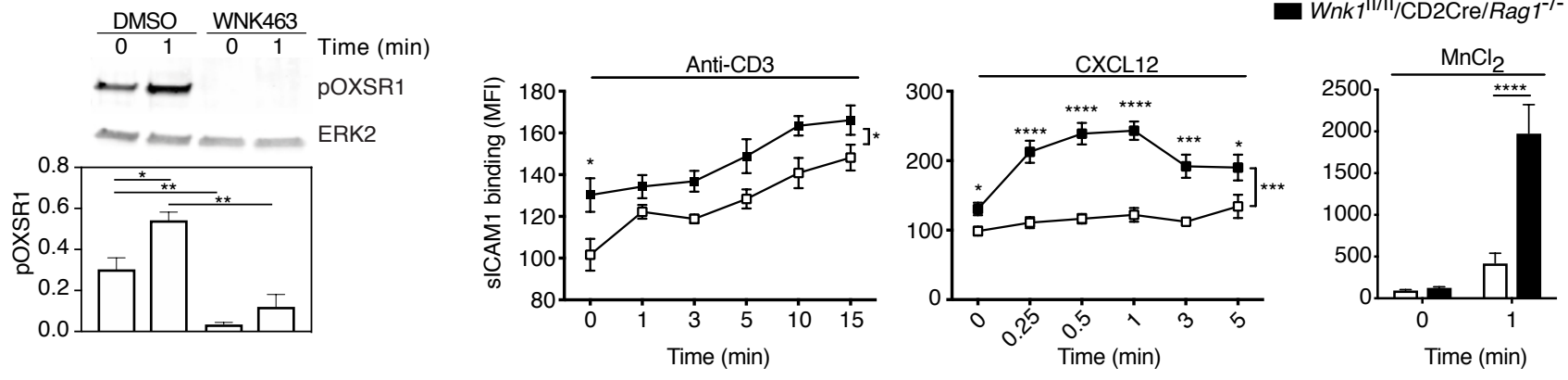

$\mathbf{F}$
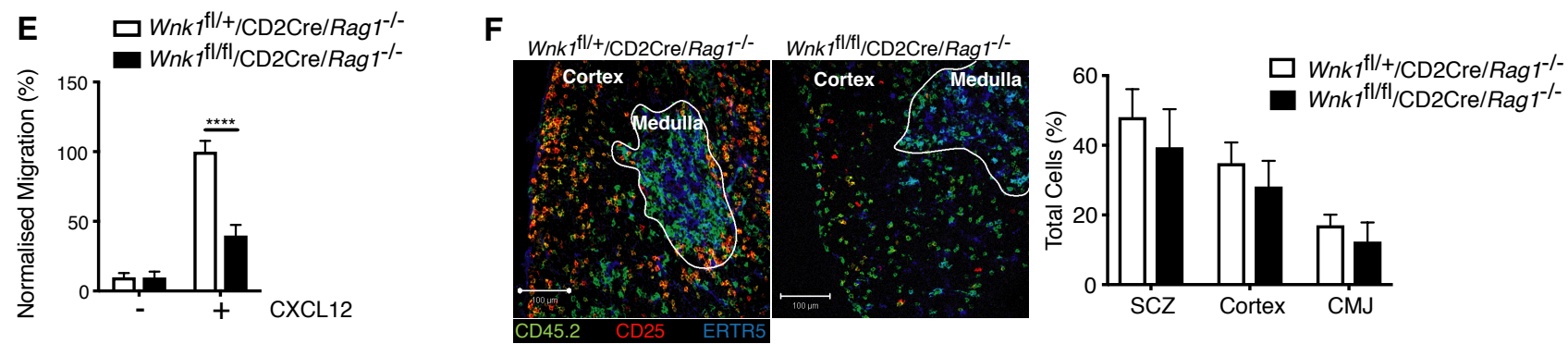

G

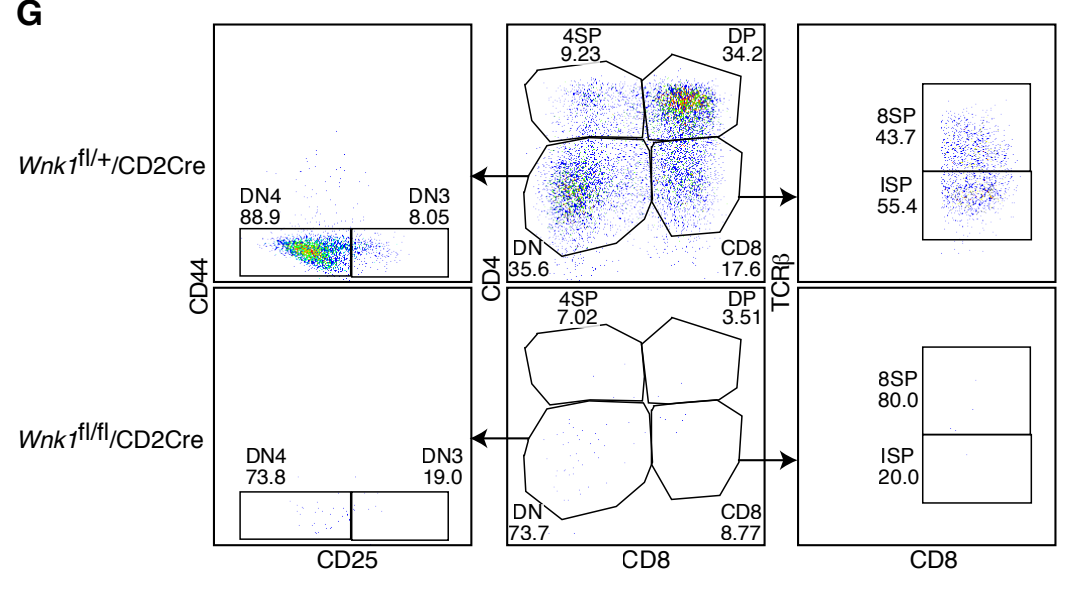

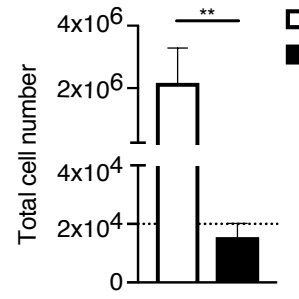

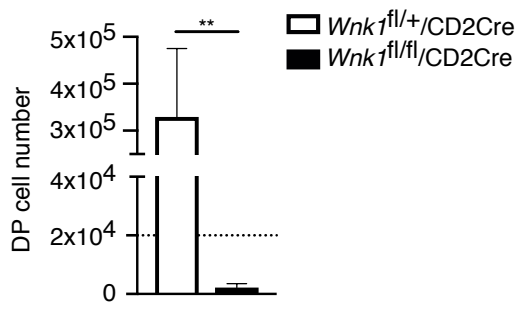


bioRxiv preprint doi: https://doi.org/10.1101/2020.06.11.147017; this version posted June 12, 2020. The copyright holder for this preprint (which was not certified by peer review) is the author/funder, who has granted bioRxiv a license to display the preprint in perpetuity. It is Figure 6

A

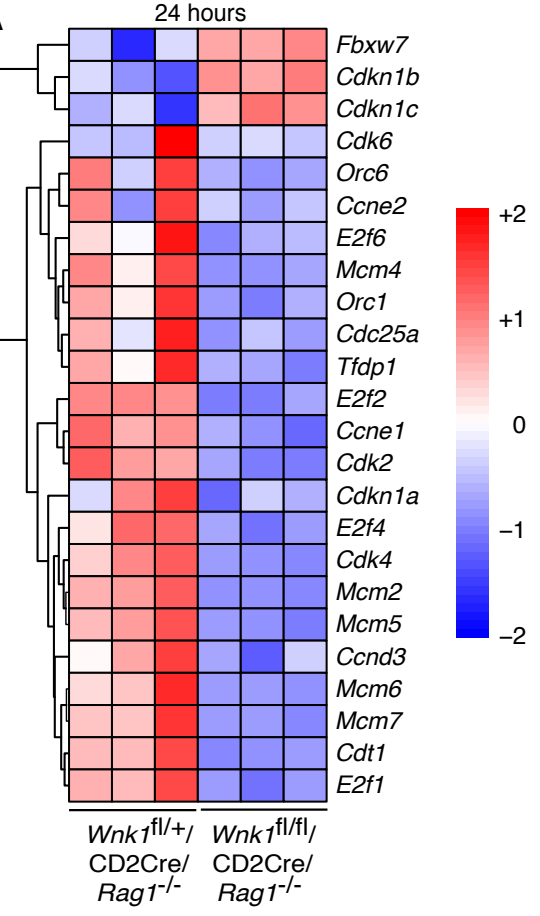

B

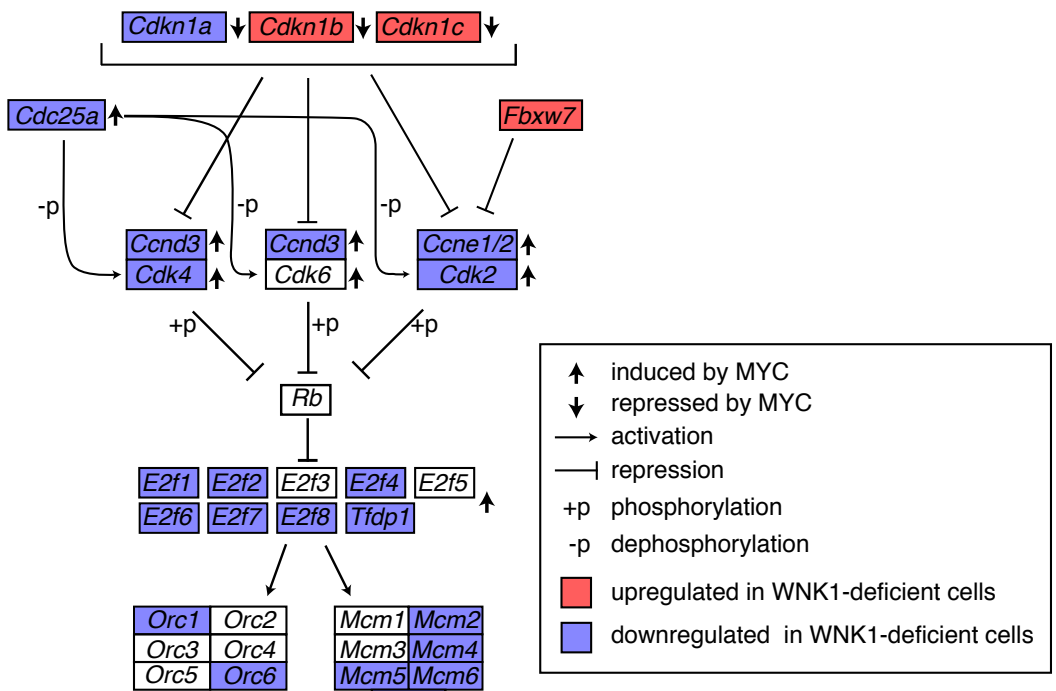

C
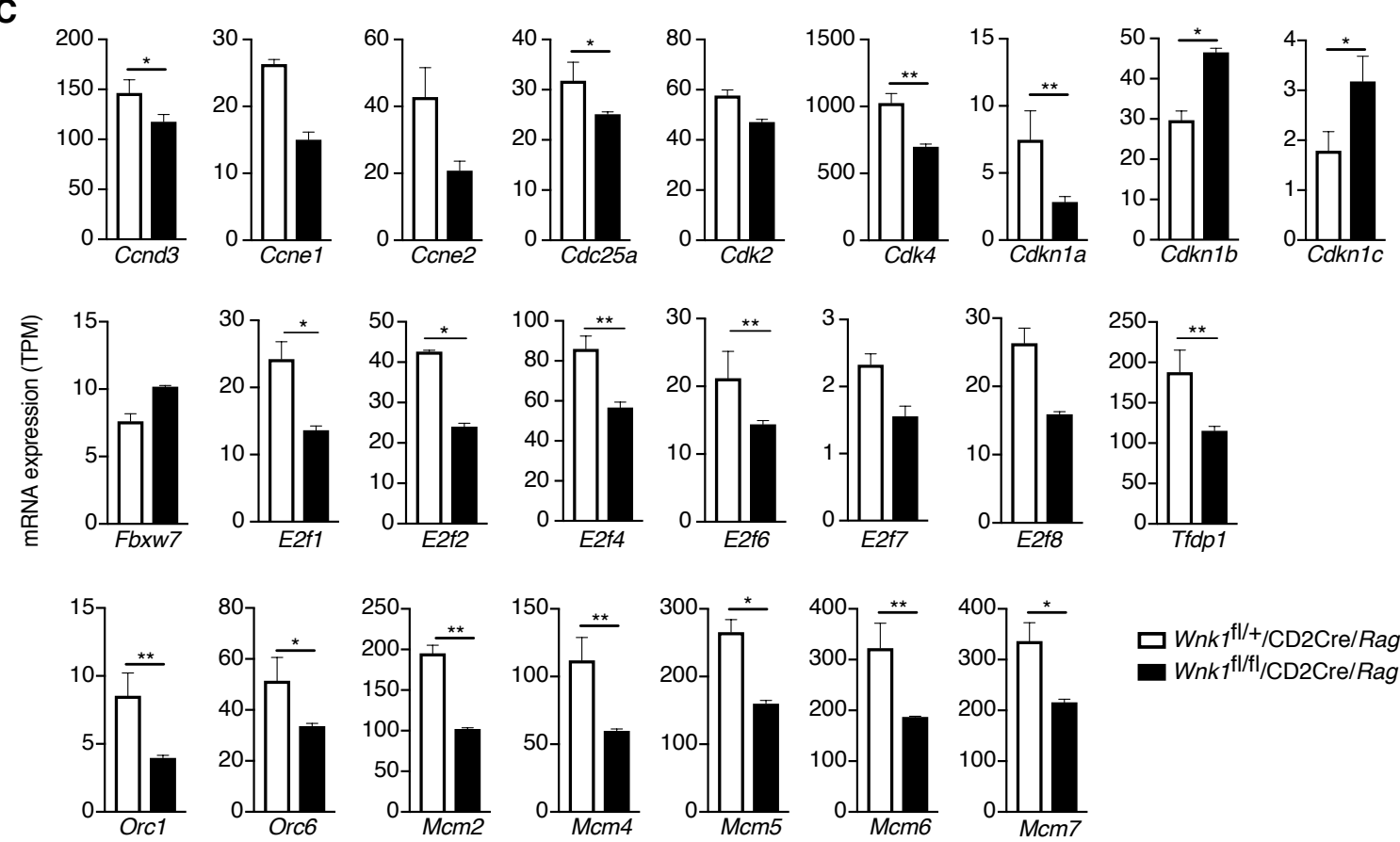

$\square W n k 1^{\mathrm{fl} / /} / \mathrm{CD} 2 \mathrm{Cre} / \operatorname{Rag} 1^{-/-}$

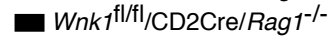

D

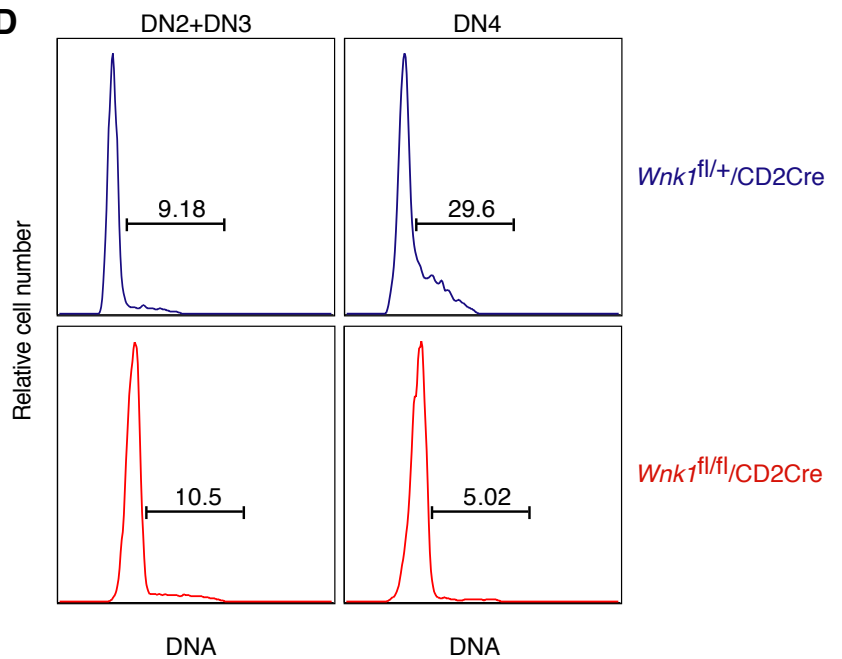

$\square W n k 1^{\mathrm{fl} / /} / \mathrm{CD} 2 \mathrm{Cre}$ - $W_{n k} 1^{\mathrm{fl} / \mathrm{fl} / \mathrm{CD} 2 \mathrm{Cre}}$

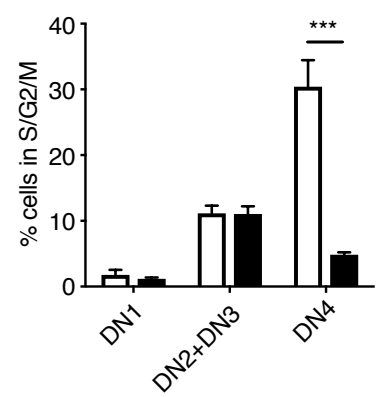

E

$\square W_{n k} 1^{\mathrm{fl} / /} / \mathrm{CD} 2 \mathrm{Cre}$ Wnk $1^{\mathrm{fl} / \mathrm{fl} / \mathrm{CD} 2 \mathrm{Cre}}$

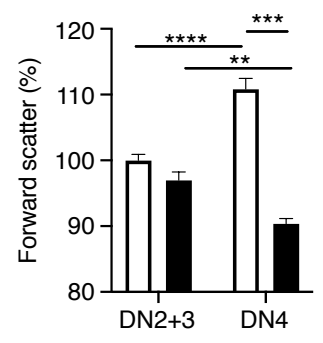


bioRxiv preprint doi: https://doi.org/10.1101/2020.06.11.147017; this version posted June 12,2020 . The copyright holder for this preprint

(which was not certified by peer review) is the author/funder, who has granted bioRxiv a license to display the preprint in perpetuity. It is Figure 7 made available under aCC-BY 4.0 International license.

A All differentially expressed genes at $24 \mathrm{~h}$

B

\begin{tabular}{|c|c|c|}
\hline Transcription Factor & Targets in dataset & $P$-value $\uparrow$ \\
\hline ETS1 & $969 / 1911$ & $9.64 \mathrm{E}-72$ \\
\hline E2F1 & $666 / 1911$ & $1.23 \mathrm{E}-38$ \\
\hline MYC & $447 / 1911$ & $4.18 \mathrm{E}-28$ \\
\hline GABPA & $604 / 1911$ & $1.06 \mathrm{E}-26$ \\
\hline TCF8 & $369 / 1911$ & $2.32 \mathrm{E}-26$ \\
\hline GLIS3 & $360 / 1911$ & $4.20 \mathrm{E}-26$ \\
\hline
\end{tabular}

Differentially expressed cell cycle genes at $24 \mathrm{~h}$

\begin{tabular}{|c|c|c|}
\hline Transcription Factor & Targets in dataset & $P$-value $\uparrow$ \\
\hline E2F7 & $20 / 80$ & $2.57 \mathrm{E}-26$ \\
\hline E2F4 & $42 / 80$ & $2.78 \mathrm{E}-26$ \\
\hline FOXM1 & $23 / 80$ & $1.93 \mathrm{E}-23$ \\
\hline MYC & $48 / 80$ & $5.37 \mathrm{E}-21$ \\
\hline E2F2 & $16 / 80$ & $7.00 \mathrm{E}-21$ \\
\hline E2F3 & $17 / 80$ & $8.09 \mathrm{E}-20$ \\
\hline
\end{tabular}
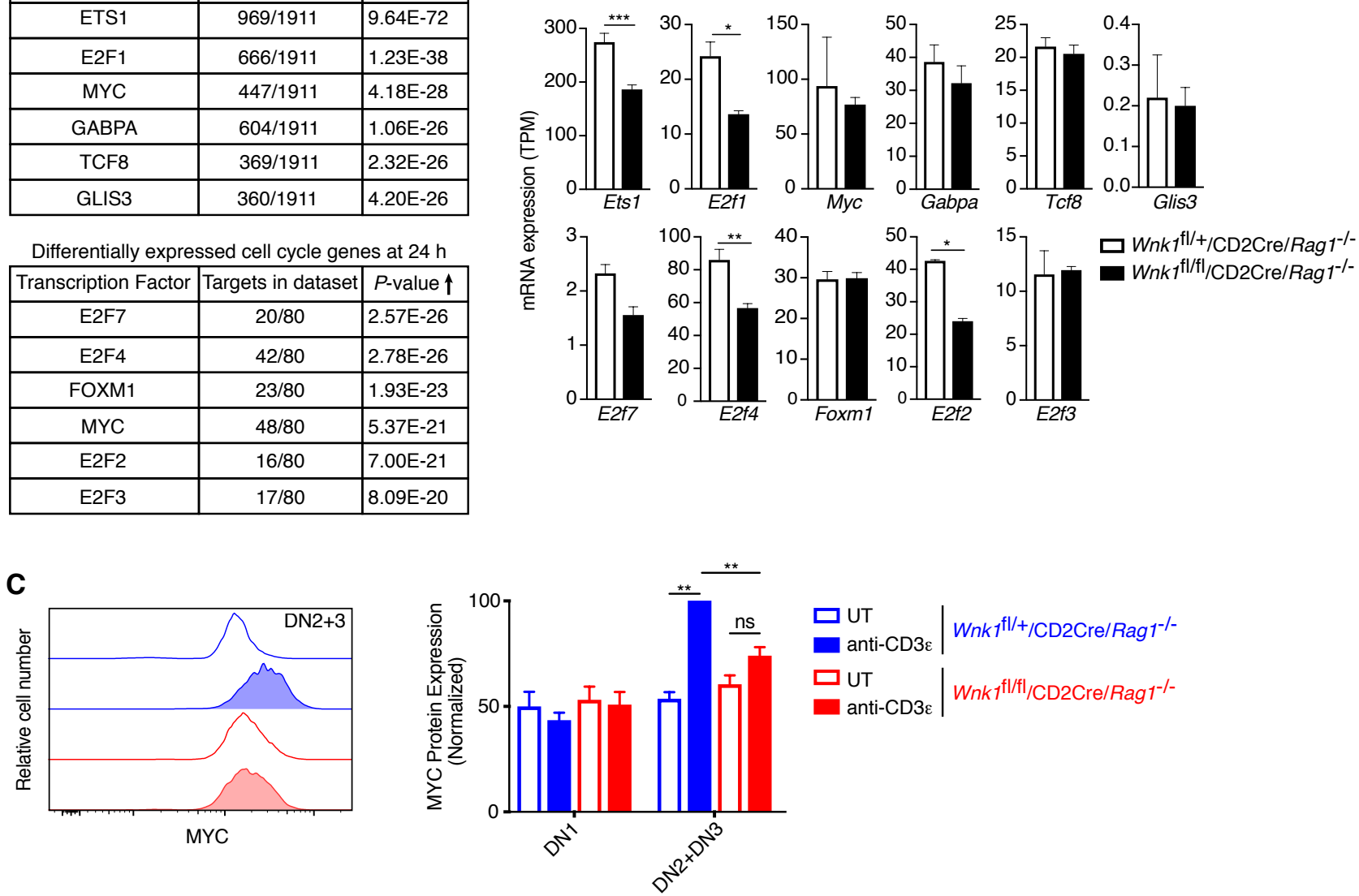

D

DN2+DN3

DN4
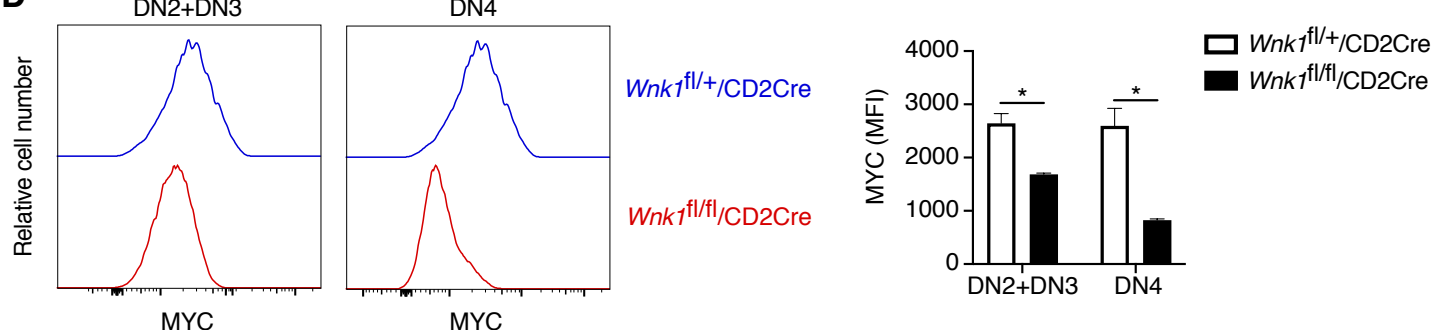

MYC

MYC 
bioRxiv preprint doi: https://doi.org/10.1101/2020.06.11.147017; this version posted June 12, 2020. The copyright holder for this preprint (which was not certified by peer review) is the author/funder, who has granted bioRxiv a license to display the preprint in perpetuity. It is Figure 8 made available under aCC-BY 4.0 International license.

A

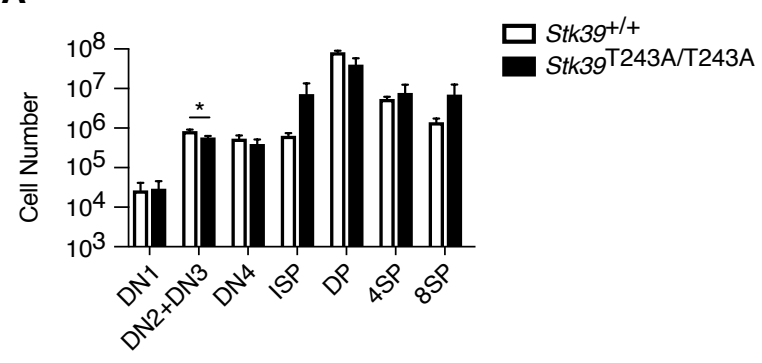

B

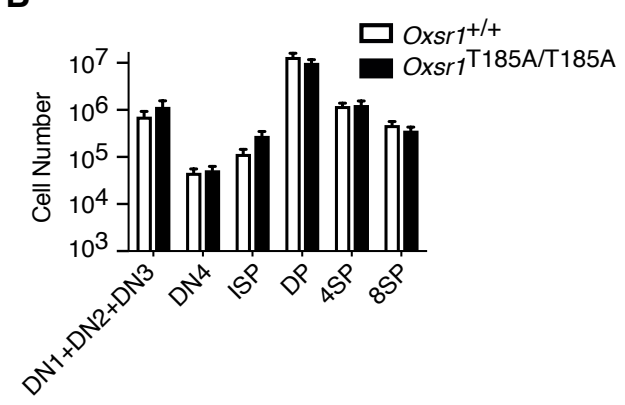

\section{C}

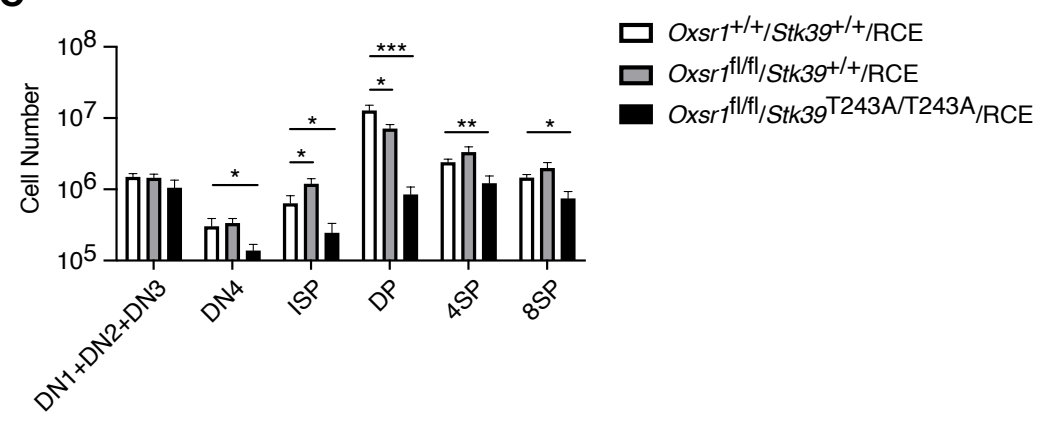

D
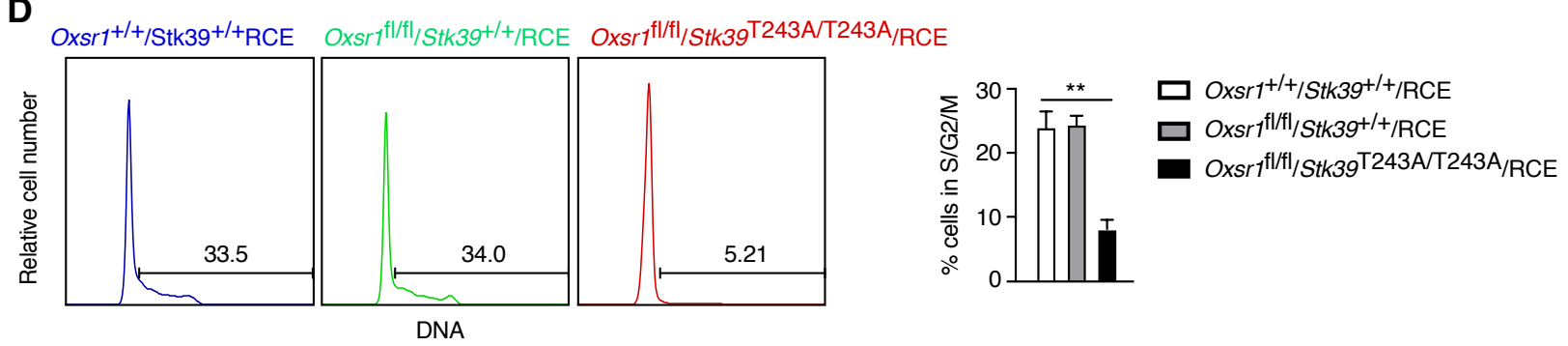

E
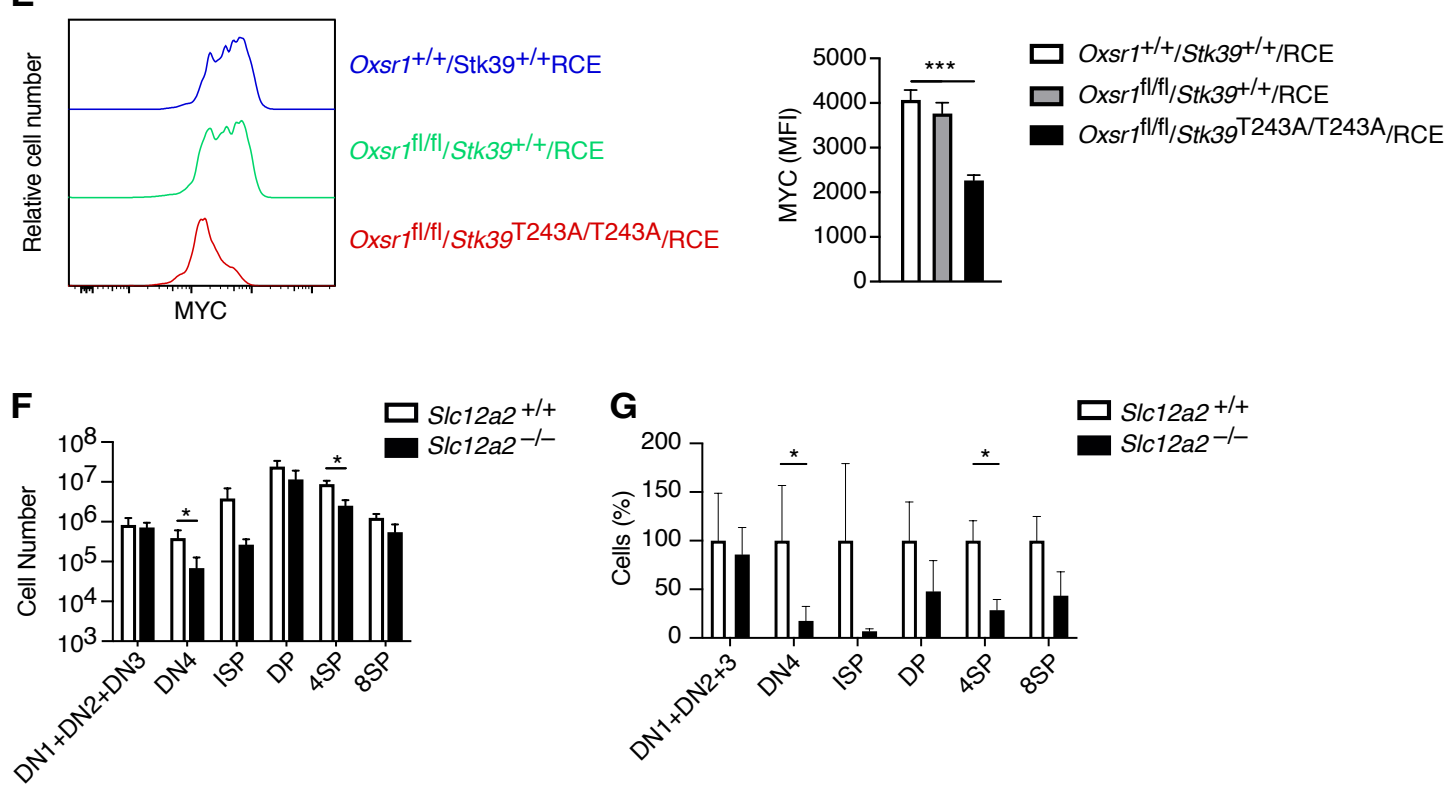
bioRxiv preprint dol: https://doi.org/10.1101/2020.06.11.147017; this version posted June 12, 2020. The copyright holder for this preprint (which was not certified by peer review) is the author/funder, who has granted bioRxiv a license to display the preprint in perpetuity. It is Supplementary Figure 1
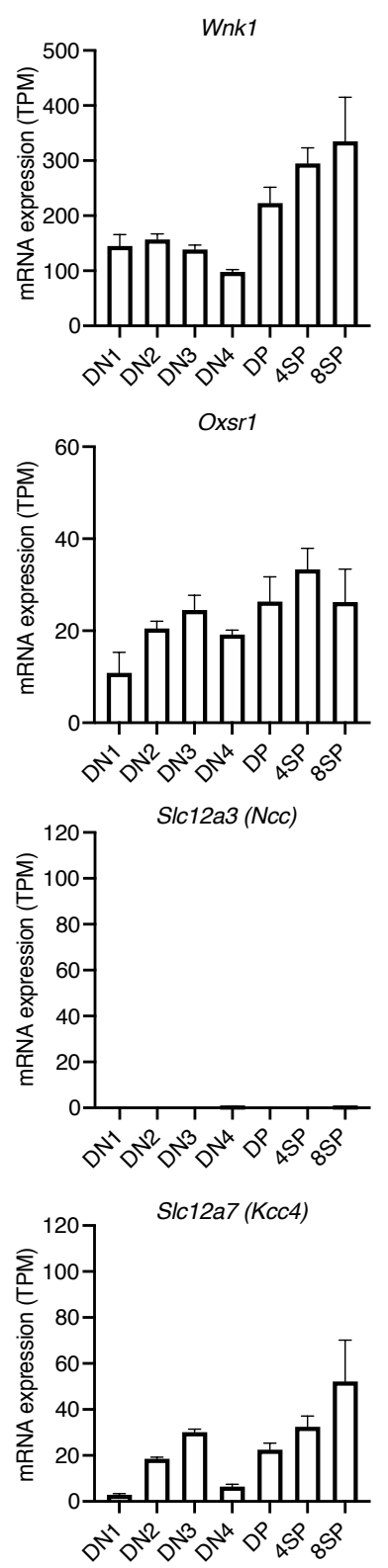

Wnk2
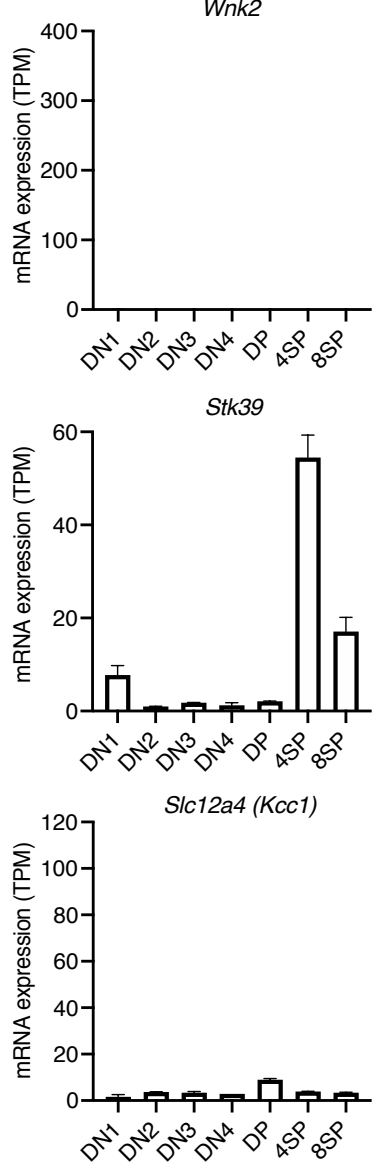

Wnk3

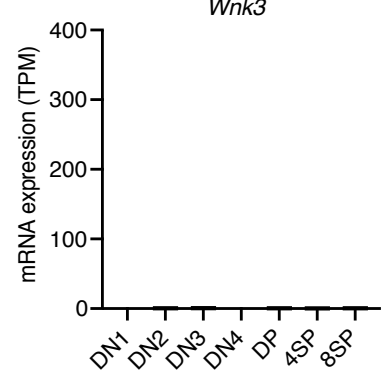

Slc12a1 (Nkcc2)

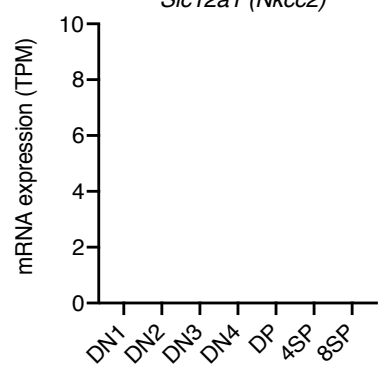

Slc12a5 (Kcc2)

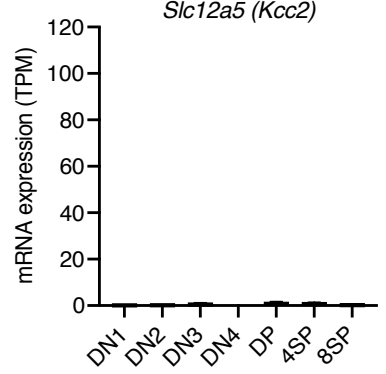

Wnk4

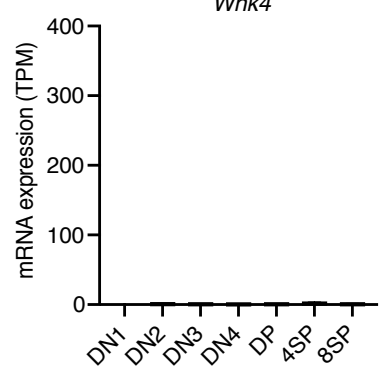

Slc12a2 (Nkcc1)
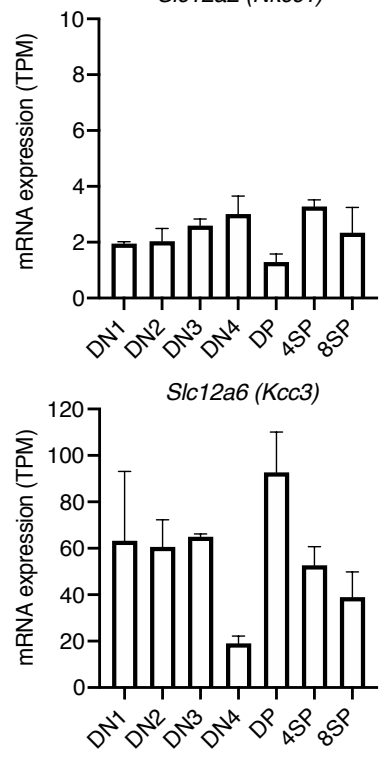
bioRxiv preprint doi: https://doi.org/10.1101/2020.06.11.147017; this version posted June 12, 2020. The copyright holder for this preprint (which was not certified by peer review) is the author/funder, who has granted bioRxiv a license to display the preprint in perpetuity. It is Supplementary Figure 2
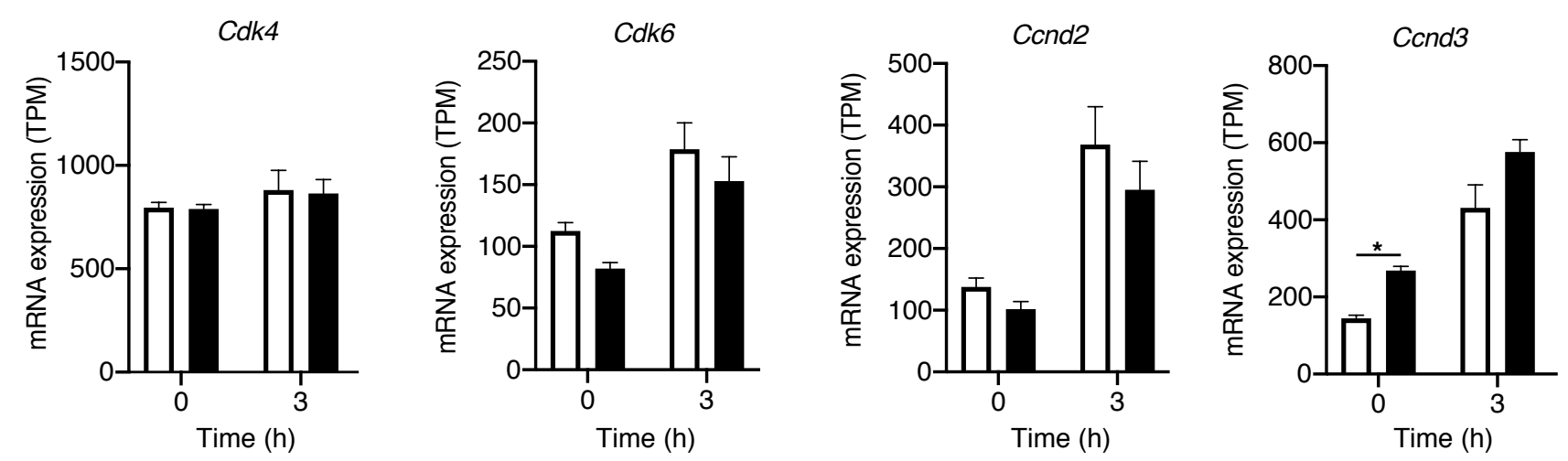

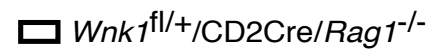

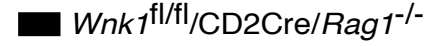


bioRxiv preprint doi: https://doi.org/10.1101/2020.06.11.147017; this version posted June 12, 2020. The copyright holder for this preprint (which was not certified by peer review) is the author/funder, who has granted bioRxiv a license to display the preprint in perpetuity. It is Supplementary Figưre 3 zailable under aCC-BY 4.0 International license.

A
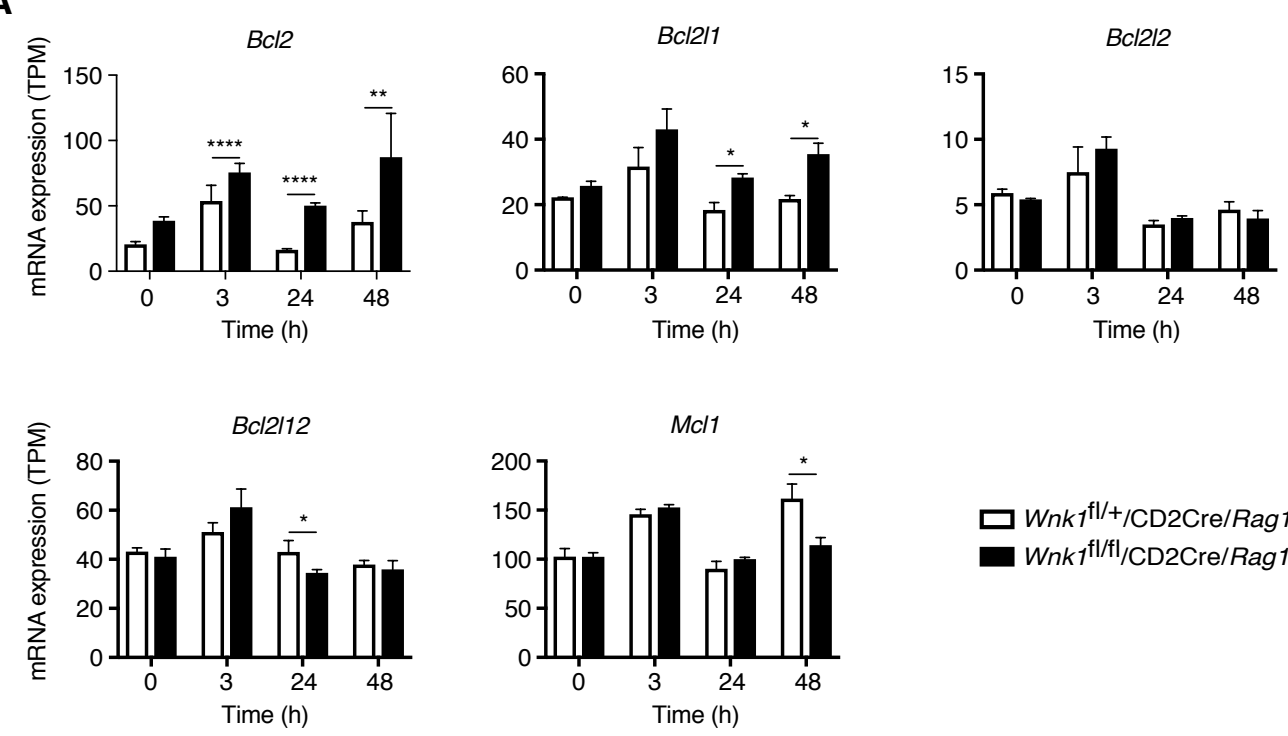

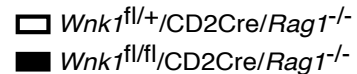

B

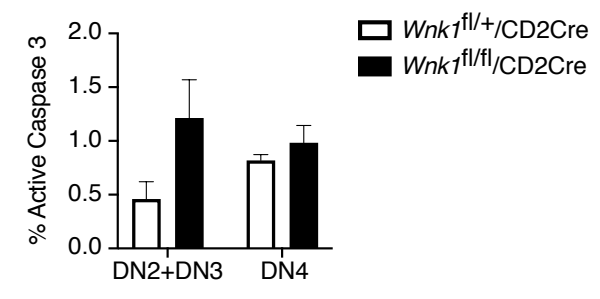

